\title{
Sentence-initial I think (that) and I believe (that)
}

\section{Prosodic evidence for use as main clause, comment clause and discourse marker*}

\author{
Nicole Dehé and Anne Wichmann \\ Freie Universität Berlin / University of Central Lancashire
}

\begin{abstract}
Sentence initial pronoun verb combinations such as I think, I believe are am biguous between main clause use on the one hand and adverbial or discourse use on the other hand. We approach the topic from a prosodic perspective. Based on corpus data from spoken British English the prosodic patterns of sentence initial $I$ think and I believe are analysed and related to their interpretation in context. We show that these expressions may function as main clause (MC), comment clause (CC) or discourse markers (DM) and that the speaker's choice is reflected in the prosody. The key feature is prosodic prominence: MCs are reflected by accent placement on the pronoun, CCs by an accent on the verb, while DMs are unstressed.
\end{abstract}

\section{Introduction}

Comment clauses (CCs) are pronoun-verb combinations such as I think, I believe, I suppose, I guess, I assume and the like (e.g. Quirk et al 1985:1112ff). As is well known, these expressions occur in various positions sentence-medially and sentence-finally. The examples in (1)a) and b) are taken from Emonds (1973:333), (1)c) is from Quirk et al (1985:1113).

(1) Sentence-final and sentence-medial CCs

a. John came later than Sue, I think.

b. John came, I think, later than Sue.

c. There were no other applicants, I believe, for that job.

While CCs have been considered parentheticals at least since Jespersen (1937), the debate in the literature between a base-generated parenthetical analysis on the one hand (e.g. Jackendoff 1972:94-100; Emonds 1973, 1976; Peterson 1999) and 
a main clause analysis involving syntactic movement on the other hand (e.g. Ross 1973) has not been settled (see also the discussion in Dehé 2009:579-582). ${ }^{1}$ Adding to the numerous works arguing for CC (and thus parenthetical) status along semantic-pragmatic lines (see Thompson \& Mulac 1991a; Aijmer 1997 among many others), recent work has provided prosodic evidence for the assumption that in positions such as (1), the target sequences are often best analysed as epistemic adverbs expressing speaker attitude, as markers used for discoursal, interactional and interpersonal purposes, or as markers of hesitant phases and mental planning or word-searching phases (Dehé \& Wichmann, to appear). ${ }^{2}$

The present paper focuses on two pronoun-verb combinations (I think, I believe) in sentence-initial position (cf. (2); (2)c) from Quirk et al 1985:1113). Our assumption, based on previous research, is that these target strings may function as main clause (MC), but that they may also function as CCs (i.e. epistemic adverbials or discourse markers), just like their medial and final relatives. ${ }^{3}$ The aim is to establish the prosodic patterns that reflect the different uses.

(2) a. I think (that) John came later than Sue.

b. I believe (that) Sue was the first one to arrive.

c. I believe that there were no other applicants for the job.

In the syntactic literature, the MC status of sentence-initial I think (that) and related expressions has often been taken for granted. In this analysis, the target verb takes an embedded clause as its complement, i.e. an embedded clausal object. This is indicated in (3).

(3) ${ }_{\mathrm{CP}}\left[\right.$ I think ${ }_{\mathrm{CP}}[($ that $)$ John came later than Sue $\left.]\right]$

A number of factors have been observed that govern the optionality of that in these and related contexts (also referred to as that-deletion in the syntactic literature). ${ }^{4}$ Among these factors are the type and frequency of matrix verb, type of matrix clause subject (pronominal vs. full noun phrase), choice of matrix subject pronoun, type and reference of embedded subject, position and function of the embedded clause, voice of the main clause (active vs. passive), ambiguity avoidance, the linear adjacency of the matrix verb and that, speech register, and the "truth claim" (Dor 2005) to the proposition of the embedded clause (see Bolinger 1972; Quirk et al 1985; Thompson \& Mulac 1991b; Biber et al 1999; Hawkins 2001; Dor 2005; Kaltenböck 2006; among others). In particular the observation that thatdeletion is only possible in complement position and only under linear adjacency between the verb and that has led to an analysis in generative syntax that accounts for the optionality of that along the lines of the Empty Category Principle (ECP) (e.g. Kayne 1981; Stowell 1981; Snyder \& Rothstein 1992). The ECP states for this particular case that the complementiser $\mathrm{C}$ can only be phonetically invisible if it is 
properly governed by the verb that selects the relevant clause. Proper government involves mutual c-command of the $\mathrm{V}$ and the $\mathrm{CP}$ whose head is $\mathrm{C}$ that. Mutual c-command is impossible under non-adjacency. The same observation has also been approached in Optimality Theory (OT) syntax, which accounts for that-deletion along the lines of syntactic constraints governing the presence, position and pronunciation of function words such as complementiser that (Grimshaw 1997, Pesetsky 1998).

Elsewhere in the literature, it has long been suggested that initial $I$ think, $I$ believe and related verbs may not have to be analysed as main clauses, but can also function as adverbial modifiers. Thompson \& Mulac (1991a,b), for example, see a development from a main clause with complementizer that, via a modifier use also in sentence-initial position but without that, towards a modifier use in sentence-medial or sentence-final positions. This cline has been questioned by Aijmer (1997), Brinton $(1996,2008)$ and Fischer (2007) on, among others, historical grounds. Instead, Aijmer (1997) suggests that the presence or absence of that is not a key factor in the decision of whether initial I think is a main clause or modifier. She sees initial $I$ think as a modifier on the grounds that a tag question added to the overall sentence refers to the rest of the sentence rather than I think. As an example, Aijmer (1997:7f) maintains that the oddness of (4)b) as opposed to (4) a) is due to the fact that $I$ think has lost its main clause status, and that therefore main clause phenomena such as tag questions apply to the clause that follows $I$ think rather than I think itself. (Note that don't you as a follow-up question in (4) b) would also be odd. $)^{5}$

(4) a. I think $\mid$ that $\mid$ Bill is at home, isn't he? b. ?? I think |that $\mid$ Bill is at home, don't I?

In a study of epistemic stance in American English, Kärkkäinen (2003) treats expressions with and without that as functionally equivalent. She suggests that $I$ think has grammaticalised to a discourse marker with discourse-organising function but with varying degrees of semantic transparency. Some occurrences are prosodically stressed and are assumed to express an epistemic stance of certainty or uncertainty; in others, an expression of stance is barely present and the discourseorganising function is primary. These cases tend to be prosodically unstressed and phonetically reduced.

In a corpus-based acquisition study, Diessel \& Tomasello (2001) distinguish three uses of mental state verbs such as think and believe, which, on the surface, take sentential complements optionally introduced by that: assertive, performative, and formulaic. Only in the assertive use does the 'main clause' (I think, I believe) express the main proposition of the overall structure. In the performative use, think and believe function as performative speech act verbs in the sense of 
Austin (1962), whose main function it is "to guide the hearer in his/her interpretation of the COMP-clause proposition" (Diessel \& Tomasello 2001: 104). In the formulaic use, they are seen as parentheticals developed from the performative use through grammaticalisation and as "holistic formula functioning as an epistemic marker or attention getter" (Diessel \& Tomasello 2001: 106).

More recently, Kearns (2007) addresses and rejects Thompson \& Mulac's $(1991 \mathrm{a}, \mathrm{b})$ proposal and argues instead that initial $I$ think etc. can be modifiers rather than main clauses even if followed by that, yet that the syntactic status of $I$ think etc. does not have to be altered in the modifier use, even with a zero complementiser. Based on earlier work by Urmson $(1952,1963)$ she provides the following criteria that help to decide between main verb and modifier use of I think etc. with or without that (see the summary in Kearns 2007:483). First, if it is the (that)-clause rather than I think that is asserted by the speaker, I think is used as modifier. Second, the target sequence can be omitted without altering the propositional content of the main assertion only if it functions as a CC. Third, if the target sequence can be paraphrased with an epistemic adverb such as probably, presumably, possibly, undoubtedly, or certainly, this indicates modifier use as opposed to main clause use. Fourth, a modifier use is suggested if the initial target sequence has corresponding clause-medial and/or clause-final forms. According to Quirk et al (1985: 1113), a clause-medial or clause-final CC is not an exact paraphrase of an initial main clause (see footnote 4 above). What Kearns (2007) seems to suggest is that if it is an exact paraphrase, the initial sequence has to be interpreted as modifier. ${ }^{6}$ Fifth, if the target sequence determines the form of a corresponding tag question, this indicates main clause status. Compare also Boye \& Harder's (2007) addressability.

On the whole, we are left with two uses: main clause vs. comment clause, where $\mathrm{CC}$ comprises adverbial or discourse use. The aim of the current study is to provide prosodic evidence that helps to disambiguate between the different interpretations. To the best of our knowledge, prosodic evidence has not previously been used directly in this debate. None of Kearn's (2007) criteria, for instance, are prosodic in nature. Kaltenböck (2007:6) considers initial I think etc. without that to be comment clauses if they are "clearly separated from the complement/host clause by means of a pause or some intervening material such as hesitation sounds ( $u h, u h m)$ or other fillers (you know, I mean)". However, pauses or hesitant phases alone are not a reliable cue to comment clause status, even in medial or final position (Dehé \& Wichmann, to appear). Moreover, it seems highly likely that in actual spoken language, main verbs may in fact be separated from their object clauses by a pause, hesitant stretch, or other kind of filler. Kaltenböck (2007) does not offer any evidence on the grounds of which his selection could be justified. Kärkkäinen (2003) offers prosodic evidence - in terms of stress placement - for the distinction 
between I think used as an expression of stance and as a discourse-organising particle. However, she does not address issues of syntactic disambiguation.

The present study is based on data from a spoken corpus of contemporary British English. Based on a careful prosodic analysis of a number of sentence-initial cases of I think, I think that, I believe and I believe that, along with an inspection of the relevant discourse contexts, we show that all four target sequences do indeed occur as main clause, comment clause and discourse marker in this position. Prosody is an important factor that contributes to the disambiguation of these uses.

In what follows, we will first present our methodology, including background information on prosodic terminology, our predictions based on the literature on related elements, and information on the source and treatment of the data used in the analysis (Section 2). The results of the data analysis will be reported in Section 3 and discussed in Section 4. The paper will close with a conclusion and outlook in Section 5.

\section{Method}

\subsection{Background 1: Prosodic terminology}

A brief introduction to the relevant prosodic terminology used here is in order, specifically the notions relating to prominence and prosodic constituency.

Prosodic constituents have been defined in a number of different approaches (see Shattuck-Hufnagel \& Turk 1996 for an overview). In the framework of Pierrehumbert (1980), Beckman \& Pierrehumbert (1986) and Pierrehumbert \& Hirschberg (1990), for example, the Intonational Phrase (IP) is intonationally defined. It is the domain of a complete intonational contour, i.e. it has at least one nuclear pitch accent, and it is terminated by a boundary tone ( $\mathrm{T} \%$; where $\mathrm{T}$ stands for 'tone' and may be high $\mathrm{H}$ or low L, and \% marks the IP edge). Similarly, Nespor \& Vogel (1986: 188) maintain that the IP is the domain of an intonation contour, and that pauses may occur at its right edge. Moreover, IP edges in their approach are defined along the lines of segmental rule application. An intonation domain (a.k.a. tone unit or tone group) in the British tradition of intonation analysis is similar to the Intonational Phrase as just described in that it, too, is defined in terms of a complete tonal contour. An intonation domain consists of an obligatory nucleus, which is optionally preceded by the prehead (any unstressed syllables preceding the head) and head (extending from the first accented syllable preceding the nucleus to the nucleus), and followed by the tail (any unstressed syllables following the nucleus before the end of the intonation domain). The structure is schematized in (5) (Crystal 1969:207f, 1972:112; optional components in parentheses). For a 
recent description of tonal contours occurring in English see, for example, Gussenhoven (2004: Chapter 15).

(5) Intonation Domain: (prehead) (head) nucleus (tail)

Along with a complete tonal contour and phonological rule application, a number of internal and external criteria have been identified that help to determine the extent of an intonation domain/IP. Domain-internally, there must be pitch movement to or from at least one accented syllable. The major patterns of nuclear tones identified in the British tradition of intonation analysis include the fall (from a high accented syllable), rise (from a low accented syllable), fall-rise, and rise-fall. Nuclear tones begin on the nucleus and cover the stretch of utterance up to the right-hand boundary of an intonation domain.

While the British tradition refers to the shape of the tonal contour, Pierrehumbert's system uses tonal targets to describe pitch accents. A fall would correspond to $\mathrm{H}^{\star} \mathrm{L}$ (a high, stressed target followed by a fall to a low target; the asterisk marks the tone associated with the stressed syllable), a rise to $\mathrm{L}^{*} \mathrm{H}$ (a low, stressed target followed by a rise). There is no equivalent for $\mathrm{T} \%$ in the British tradition. Instead, "British nuclear tones such as fall-rise conflate the pitch movement on the last accent (e.g. fall) with the pitch movement at the end of the phrase (e.g. rise)" (Ladd 1996: 88). At the end of an intonation domain, a fall-rise would thus correspond to $\mathrm{H}^{\star} \mathrm{L}+\mathrm{H} \%$, a rise-fall to $\mathrm{L}^{*} \mathrm{H}+\mathrm{L} \%$.

Pauses, both filled and silent, have also been considered boundary markers (e.g. Nespor \& Vogel 1986:188). However, since they are not obligatory and their occurrence, length and position depend on a number of factors (see Krivokapić 2007 for a recent overview), pauses cannot be considered reliable cues. It is therefore important to distinguish between structure-related (breath-)pauses on the one hand, and hesitational or performance-related stretches on the other hand. Potentially more reliable cues include pitch reset (Gussenhoven 2004 and references given there), and domain-final lengthening (see Vaissière 1983; Gussenhoven \& Rietveld 1992; Ferreira 1993, among many others). Furthermore, a change in pitch level and/or direction on unaccented syllables following a nuclear tone has been seen as "a fairly clear boundary marker" (Cruttenden 1997:34). Specifically, after falling tones that are followed by low unaccented syllables there is a step-up to the pitch level of the unaccented syllables at the beginning of a new intonation domain, while after rising tones, there is "a step-down to the pitch level of any unaccented syllables at the beginning of the following" domain (Cruttenden 1997:34).

The work documenting the prosodic transcription and labelling in the Lancaster/IBM Spoken English Corpus is of further interest with regard to the corpus data, (see Knowles 1991). The boundary cues fall into three categories: temporal discontinuities, which essentially include silent and filled pauses and final 
lengthening, and combinations of these; pitch discontinuities, which essentially correspond to Cruttenden's (1997) change in pitch level as outlined above; and segmental discontinuities, which refer to processes of connected speech such as the blocking vs. presence of assimilation, elision, $r$-linking, $[j, w]$ glides after close vowels, gemination of stop phases, and contractions (Knowles 1991: 151ff).

In the present study, prosodic boundaries in the immediate vicinity of the target sequences were analysed and pitch accents were identified on the basis of these criteria.

\subsection{Background 2: The prosody of main clauses and comment clauses}

Main clauses (MC) are clauses that express the main proposition of an overall utterance. ${ }^{7}$ They have predicative force. If one of the arguments (e.g. internal argument of the verb) is clausal, the $\mathrm{MC}$ is superordinate and the clausal argument is subordinate. The omission of MCs leads to unacceptability or a substantial change in meaning. The focus of an MC like I think or I believe is on the mental state of the speaker: on his/her attitude, opinion or true belief. Syntactically, it is possible to focus on the $\mathrm{MC}$ in a tag or follow-up question. The subordinated argument clause expresses another proposition, viz. what is thought/believed by the speaker. The relevant use of think is assertive in Diessel \& Tomasello's (2001) sense, and primary lexical in Boye \& Harder's (2007) sense. On the other hand, I think and I believe used as CCs or discourse markers (DMs) are used in the performative or formulaic way discussed in Diessel \& Tomasello (2001). The main proposition is expressed in the apparent subclause, while the apparent main verb reflects the speaker's stance towards the proposition or functions as an epistemic marker. In this use, the omission of I think or I believe does not alter the overall meaning.

In order to decide between the MC and CC status of I think (that) and I believe (that) on prosodic grounds, we first have to look at the respective prosodic properties and their relation to meaning. We will begin by looking at CCs. As shown most recently by Dehé (2009:593-598), syntactically unambiguous CCs in non-initial position come in a variety of prosodic patterns. They may be phrased in a separate IP, or they may be integrated into an IP formed together with material from their host clause. Regarding prominence, integrated CCs may be unstressed, or they may have prenuclear or nuclear stress on either the pronoun or the verb. There is thus no unambiguous prosodic pattern of syntactically unambiguous CCs.

With regard to meaning, recent work on the prosodic properties of non-initial CCs has shown that they are often best analysed as epistemic adverbs expressing speaker attitude, as markers used for discoursal, interactional and interpersonal purposes, or as markers of hesitant phases and mental planning or word-searching phases. Dehé \& Wichmann (to appear) argue that transparent, propositional 
meaning expressing speaker attitude such as genuine uncertainty, belief or doubt is prosodically coded such that the relevant sequences are phrased separately, i.e. they form their own intonation domains and bear a nuclear prominence on either the pronoun or the verb. This is usually a falling(-rising) tone, but occasionally, in the final position in particular, a rising tone. Prosodically separate, prominent instances of non-initial CCs are treated by Dehé \& Wichmann (to appear) as epistemic markers of stance. Prosodically integrated, and, crucially, unstressed, non-initial CCs are analysed by Dehé \& Wichmann (to appear) as grammaticalised elements that are "clearly of epistemic derivation" but "contribute little to the truth value of the proposition". Dehé \& Wichmann "take them to have a discoursal or interactional function - creating narrative cohesion, or simply a courteous gesture of modesty or politeness towards the hearer". These findings are in line with results regarding other high frequency adverbial elements that are on a cline of grammaticalisation from propositional to discourse meaning, such as well, now (Hirschberg \& Litman 1993) and of course (Wichmann et al, to appear).

Moving on to comparable elements in sentence-initial position, the intonation of initial sentence adverbials has been described in some detail by Allerton \& Cruttenden (1974). Given that CCs are typically elements that express the speaker's attitude or provide a comment on the proposition of the rest of the utterance, their interpretation corresponds closely to the group of message-oriented sentence adverbials, which Allerton \& Cruttenden subdivide into likelihood adverbials (e.g. certainly, definitely, obviously, possibly, presumably, probably) and attitudinal adverbials (e.g. fortunately, surprisingly). According to Allerton \& Cruttenden (1974:13), these adverbials, like several other types, "can occur in initial position without a main accent, i.e. they can occur as part of the pre-nuclear tune. [...] When occurring as part of the pre-nuclear tune, most adverbials have a stress and this will often constitute one of the steps of a 'stepping head'". They also mention "a level tune in sentence-initial position". In other words, these are all integrated and stressed. When sentence-initial attitudinal adverbials are separate and carry a nuclear tone, they always bear a fall-rise (Allerton \& Cruttenden 1974: 15). The intonation of likelihood adverbials, on the other hand, is more complex and depends, inter alia, on the newness/givenness of the material in the sentence they occur with, and on whether or not they cast doubt on the utterance (Allerton \& Cruttenden 1974:15-18). Generally, if they are nuclear, they can be separate with a fall or fall-rise, or they are followed in their domain by material from the following clause which forms either a falling or rising tail. For initial (potential) discourse markers, it has been claimed by Hirschberg \& Litman (1993), for example, that they often occur as the unstressed prehead in a larger intonation phrase. Generally speaking, in a theory of intonational meaning (e.g. Pierrehumbert \& Hirschberg 1990), the degree of a word's prosodic salience is related to its meaning. Words 
with the greatest semantic weight have a greater potential to attract (sentence) stress than grammatical or function words, which are normally unstressed and frequently reduced.

Next, we consider the prosody of main clauses in a context such as the one under investigation. According to prosodic theory (e.g. Nespor \& Vogel 1986; Selkirk 1986, 1995; Truckenbrodt 1995, 1999), which has as its input the output of syntactic structure, a phrasal boundary should not occur after think or believe under the main clause analysis. Constraints like AlignXP (edge alignment; Selkirk 1986) and Wrap (Truckenbrodt 1995) predict a boundary after the complete verbal phrase, i.e. after the verb and its complement, but not immediately after the verb. On the other hand, constraints on the size of prosodic constituents (e.g. Gee \& Grosjean 1983; Nespor \& Vogel 1986; Ghini 1993; Selkirk 2000) would predict that if the verbal complement is complex, as is the case for a phrasal one, all might not be phrased together. For example, Nespor \& Vogel (1986: 198f) observe that a long IP may be restructured such that a boundary is inserted between a main verb and its clausal argument, e.g. between a main verb and a that-clause. It follows from this that the phrasing of an initial MC may vary according to the overall context, including factors such as the length and complexity of the clausal argument, and speech rate. If the MC is phrased in a separate IP, it must bear a main prominence on one of its elements. If it is prosodically integrated with its clausal argument, the MC may, but need not be the locus of a nuclear or prenuclear prominence.

To summarise, according to previous research, the prosodic patterns of noninitial CCs, initial S-adverbials and initial MCs may be as given in (6) through to (8); square brackets indicate prosodic phrasing.

(6) Non-initial CCs and DMs
a. $\quad[\ldots][\mathrm{PRN} V][\ldots]$
accent on PRN or $\mathrm{V}$
b. $[\ldots][\ldots \mathrm{PRN} V][\ldots]$
c. $[\ldots][\mathrm{PRN} V \mathrm{\ldots} \ldots][\ldots]$
accent on PRN or $\mathrm{V}$, or unstressed
d. $[\ldots][\ldots$ PRN $V$...] $[\ldots]$
accent on PRN or V, or unstressed
accent on PRN or $\mathrm{V}$, or unstressed

(7) Initial S-adverbials
a. $\quad[\operatorname{Adv} \ldots][\ldots]$
adverb with pre-nuclear accent
b. $\quad[\operatorname{Adv}][\ldots]$
adverb with nuclear accent

(8) Initial MCs (of the form pronoun $V$ )
a. $\quad[P R N ~ V][\ldots][\ldots]$
accent on PRN or $\mathrm{V}$
b. $[$ PRN V ...] [...]
accent on PRN or V, or unstressed

It follows from this that syntactically unambiguous MCs, which are comparable in form to the sequence under investigation here, as well as syntactically unambiguous non-initial CCs do not exhibit unambiguous prosodic patterns with respect to 
accent location and phrasing. In the present context, the decision of what is and what is not a $\mathrm{MC}$ can therefore not a priori be taken on prosodic grounds along the lines of a direct comparison between initial I think/believe (that) and unambiguous MCs and CCs. However, we will show that the function of initial $I$ think/believe (that) is reflected in the prosody and that prosody is used to disambiguate between meanings in sentence-initial position.

\subsection{Data source and data selection}

The data for this study were drawn from the spoken part of the British Component of the International Corpus of English (ICE-GB version 3.0; cf. Nelson, Wallis \& Aarts 2002) which contains approximately 640,000 words from various text types, ranging from direct casual conversations and private telephone calls to scripted monologues and broadcast news, all recorded in the 1990s. The sequences discussed here were ultimately retrieved by manual search. Since a previous search for medial and final CCs in the same corpus yielded the highest frequencies for the three verbs think, believe, and suppose (see Dehé \& Wichmann, to appear), the initial automatic search included the strings I think, I think that, I believe, I believe that, I suppose, and I suppose that. Non clause-initial combinations were then excluded by manual sorting. Only seven tokens were found of I suppose that, and suppose was therefore not considered further. Since other verbs typically occurring as CCs (guess, assume, reckon, understand, imagine, suspect, etc.) were even less frequent in the corpus, the present study concentrates on the verbs think and believe.

The search yielded 24 cases of $I$ believe directly followed by a clause introduced by that (henceforth I believe that), 22 cases of I believe directly followed by a clause without that (henceforth $I$ believe $\emptyset$ ), 88 cases of $I$ think that and 839 cases of $I$ think $\emptyset$. Further data selection and sorting was based on the following criteria. First, only those data entered the analysis for which sound files were available and of good enough quality to allow for an acoustic analysis. Second, to exclude the factor of linear adjacency (see the discussion in Dor 2005:370ff), examples that had adverbials or other material between the pronoun-verb sequence and that were disregarded. Third, in order to control for speech register (see e.g. Aijmer 1997: 9f; Biber et al 1999: 14 and 680f; Dor 2005:369f), the sets of target items were divided into items from the public domain representing more formal conversation and items from the private domain representing more casual conversations. ${ }^{8}$ After this procedure, all available cases of $I$ believe that and $I$ believe entered the analysis. Specifically, 21 cases of I believe that entered the analysis. Of the original 24 tokens, three could not be included because their sound files were unavailable. All remaining 21 tokens were from the public domain. No instances of $I$ believe that 
were found in the private domain. 21 cases of $I$ believe $\varnothing$ also entered the analysis. Of these 21 , only one item was from the private domain, while 20 were from the public domain.

As follows from the numbers given above, initial $I$ think that and I think $\emptyset$ were far more frequent. Of the 88 cases of $I$ think that retrieved from the corpus, 20 were from the public domain. All 20 entered the analysis. Of the 839 cases of $I$ think $\varnothing$ originally retrieved from the corpus, 480 were from the public domain. Of these 480 instances, 20 were selected according to the criteria outlined above and the additional condition that they represented the same text types as the selected cases of $I$ believe $\varnothing$. After that, a random selection assured matching numbers of analysed $I$ believe $\varnothing$ and $I$ think $\varnothing$.

As indicated, all these items represented speech in public. I believe that and $I$ believe $\varnothing$ were virtually absent from the private domain (with the exception of one token of $I$ believe $\varnothing$ ). However, 68 (out of 88) cases of initial I think that and 359 (out of 839) cases of $I$ think $\varnothing$ were from the private domain. Of these tokens, 20 cases each of $I$ think $\varnothing$ and I think that were selected to allow for a comparison between the private and public domains. The analysis of these items revealed no differences in prosodic behaviour or the prosody-meaning relation between the public and private domains. In reporting on and discussing the results we will therefore concentrate on the tokens from the public domain. The list in (9) below summarises the data investigated here. Examples are given in (10) through (13).

(9) Data (all from the public domain)
a. 21 cases of $I$ believe that
b. 20 cases of I believe $\emptyset$
c. 21 cases of $I$ think that
d. 20 cases of $I$ think $\emptyset$

(10) Sentence-initial I believe that:

I believe that good maps will help good decision-making which will protect and enhance our environment (ICE-GB: s2b-045 \#19)

(11) Sentence-initial $I$ believe $\emptyset$ I believe both Parliament and sterling have served our country and the rest of the world very well (ICE-GB: s1b-053 \#72)

(12) Sentence-initial I think that: I think that Mrs Thatcher doesn't really represent the British people in her over-the-top attitude to the Gulf War (ICE-GB: s1b-035 \#19)

(13) Sentence-initial I think $\varnothing$ I think he would be an extremely good leader of a cabinet (ICE-GB: s2b-009 \#74) 


\subsection{Data treatment and analysis}

All items were subjected to an auditory, and, if at all possible, an instrumental analysis. In the auditory analysis, the locations and types of pitch accents and pauses were identified, and the overall prosodic structure of the utterance was described. In particular, the auditory analysis helped to establish whether or not one of the elements of the target sequence was prominent. If there was a local prominence, the exact location (pronoun or verb) and type of pitch accent was identified. Along with the type and location of pitch accents on the target sequence, any pitch accents in its vicinity were located and its type(s) specified. For the purpose of the instrumental analysis, the larger sound files as retrieved from the corpus materials were edited into individual files containing the target sequence and as much additional material as necessary for the analysis. The instrumental analysis was done in Praat (Boersma 2001; Boersma \& Weenink 2008), which was also used to visualise and print the tonal contour. Praat was used to identify the tonal contours associated with the target sequence and with the material in its immediate environment, including pitch accents and boundary tones in target positions, as well as to measure the length (in milliseconds; ms) of pause(s) in the vicinity of a target sequence. Domain boundaries were established following the criteria discussed in the literature (see Section 2.1 above). ${ }^{9}$ The key criteria are summarised in (14) and addressed in turn below. All items were analysed by the authors.

(14) Criteria for the identification of an IP/intonation domain
a. domain-internal criteria:
a1. complete tonal contour (CTC)
a2. domain across which declination applies
b. external criteria:
b1. presence and nature of pauses
b2. pitch on unaccented syllables following a nuclear tone
b3. domain-final lengthening
b4. presence or absence of connected speech processes

The domain-internal criteria in (14)a) are tonal features that apply across the target domain. As outlined in Section 2.1, the IP/intonation domain is intonationally defined in terms of a complete tonal contour (CTC). The pitch accents and boundary tones were identified for each target domain, i.e. the domain(s) spanning the target sequence $I$ verb (that). The IP/intonation domain is also the domain across which declination applies such that later pitch peaks within an IP are downstepped with regard to earlier ones, and pitch reset indicates a new domain (see Ladd 1986, 1996), although pitch peaks in later domains may not be reset to the same maximum level as pitch peaks in earlier domains (Ladd 1986). 
The external criteria listed in (14)b) apply at boundaries between domains. First, all pauses were identified and their length measured. Structure-related breath pauses, but not pauses due to performance factors such as hesitational stretches, were interpreted as boundary markers. Second, the pitch on unaccented syllables following a nuclear tone was studied. Pitch discontinuities and a step-up in pitch on an unaccented syllable after a nuclear fall, and a step-down in pitch on an unaccented syllable following a rise were seen as evidence for a boundary. Pitch continuation, i.e. a continuous rise or fall or no change in pitch level/direction in a target position, was taken as evidence against a boundary. Third, final lengthening, in particular the lengthening of the very last syllable of a domain, the last stressed syllable and the last word, was taken into account but served only as an impressionistic factor. A systematic analysis of this factor was impossible due to the nature of the data. Finally, the presence or absence of connected speech processes such as assimilation, elision, etc., was taken into account, but not analysed systematically since, due to the nature of the corpus data, it was impossible to control for possible environments for the blocking or application of these processes (see also Knowles 1991: 155).

The analytic procedure is exemplified for the token given in (15), plotted in Figure 1. Here and below, the dashed vertical lines represent segmental (word or syllable) boundaries. Solid vertical lines mark relevant tonal landmarks. Square brackets in the example represent intonation domain boundaries.

(15) a. [... I think that he is the most neglected of that uh number of composers around the turn of the century (ICE-GB: s1b-032 \#103)

b. [ I think] [that he is the most ne glected]

$$
\mathrm{H}^{*} \mathrm{~L} \quad \mathrm{H} \% \quad \mathrm{H}^{*} \quad \mathrm{H}^{*} \quad \mathrm{H}^{*} \mathrm{~L} \mathrm{~L} \%
$$

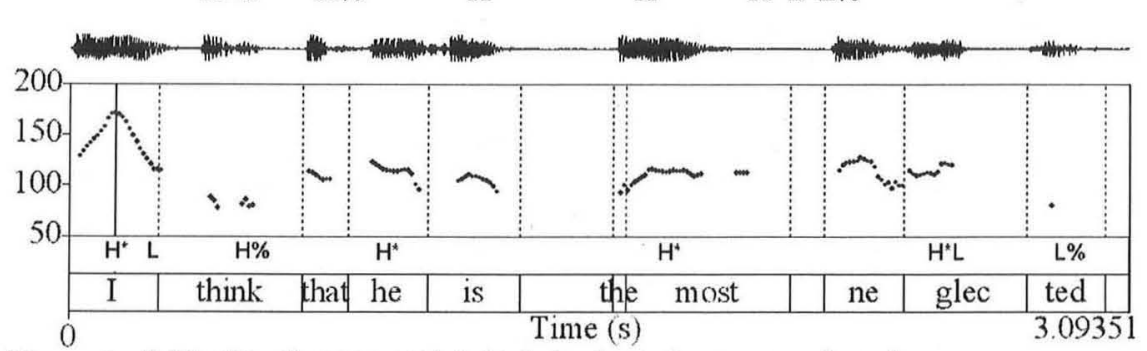

Figure 1. (ICE GB: s1b 032 \#103) I think that he is the most neglected

The following boundary criteria suggest the phrasing in (15)b). The target sequence is the domain of a CTC (see (14)a1)), specifically a fall-rise ( $\left.\mathrm{H}^{*} \mathrm{LH} \%\right)$. The nuclear peak is associated with the pronoun $I$. Moreover, the domain of the target sequence is one across which declination applies (see (14)a2)). There is a pitch discontinuity between think and that, followed by a step-up in pitch on that (see 
(14)b2). Also, that occurs in a reduced phonetic form which is not usually found at the end of a domain, but is common at the beginning of a domain (e.g. Selkirk 1996). The following material that he is the most neglected is all phrased in one domain with a complete CTC such that there are prenuclear accents on he and most and a nuclear fall associated with the stressed syllable of neglected. Note that the apparent pauses between is and the and between most and neglected do not mark domain boundaries but are due to the speaker's staccato way of speaking.

In what follows, we will first report on the results of the prosodic analysis. We will then show how the interpretation of a selection of target sequences is reflected in the prosody. Finally, we will demonstrate that the findings are compatible with previous research on the prosody of unambiguous MCs, CCs and DMs.

\section{Results}

\subsection{Prosodic patterns}

The prosodic patterns of one instance of $I$ believe that and one instance of $I$ think that remained unclear even after careful auditory and instrumental analyses by both authors. They were discarded from the data, leaving 20 items in each group. Across these data, the prosodic patterns listed in (16) were found. As above, square brackets represent intonation domain boundaries; accent positions are bold-printed. Examples are given directly below. The numerical distribution will be summarised in Table 1 at the end of this section.

(16) Prosodic patterns found with initial I think (that) and I believe (that)

a. Inside the target sequence, only the pronoun (PRN) is prominent

a1. prosodic separation, nuclear accent on the pronoun [PRN V] [(that $). .$.

a2. prosodic integration as head; prenuclear accent on the pronoun [PRN V (that) ...]

b. Inside the target sequence, only the verb (V) is prominent

b1. prosodic separation, nuclear accent on the $\mathrm{V}$ [PRN V] [(that $)$...]

b2. prosodic separation, nuclear accent on the $\mathrm{V}$ [PRN V that $][\ldots]$

b3. prosodic integration as head; prenuclear accent on the $\mathrm{V}$ [PRN V (that) ...]

c. Target sequence remains unstressed; prosodic integration as prehead [PRN V (that) ...] 
Pattern (16)a1), prosodic separation with a nuclear accent on the pronoun, is illustrated by example (15), Figure 1, above. Pattern (16)a2), prosodic integration with a prenuclear accent on the pronoun, is represented in (17)/Figure 2. The whole sequence I think that Lord Scarman was right forms one intonation domain, with two high prenuclear pitch accents associated with the pronoun $I$ and the first syllable of Scarman, respectively, and a nuclear falling-rising pitch accent on right. Prenuclear prominence thus falls on the target sequence. There is no reason to assume the presence of a domain boundary anywhere within or directly after the target sequence. Rather, we find a continuous, downstepped pitch contour. ${ }^{10}$

(17) a. I think that Lord Scarman was right when he said that our accountability for the police in this country was muddled and incomplete (ICE-GB: s1b-033 \#37)

b. [ I think that Lord Scarman was right] $\mathrm{H}^{*} \quad ! \mathrm{H}^{*} \quad ! \mathrm{H}^{*} \mathrm{~L} \mathrm{H} \%$

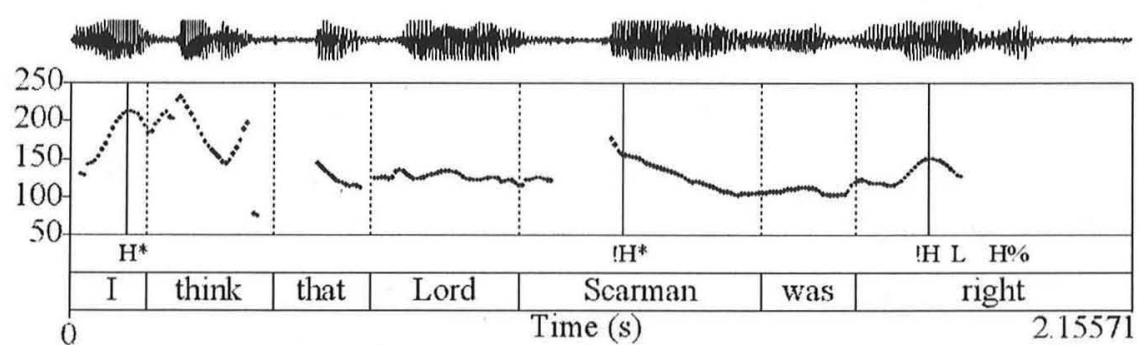

Figure 2. Integration as head; prenuclear pitch accent on the pronoun

Moving on to (16)b), accent on the V, example (18)/Figure 3 illustrates (16)b1): $I$ believe is phrased separately with a nuclear accent on the verb. The relevant local peak is marked by the solid vertical line and is annotated $\mathrm{H}^{*}$ on the tonal tier. That is present but is phrased with the material that follows. The domain boundary is clearly identifiable due to the lengthening of believe, the pitch discontinuity between believe and that, and the following step-down in pitch on that (which is clearly audible but not visible from the pitch contour due to the incompletely plotted final rise on believe).

(18) a. I believe that I'm the last survivor of the commission (ICE-GB: s2b-025 \#127)

b. [I be lieve $\quad$ [that ...]

$\mathrm{H}^{*} \mathrm{~L} \mathrm{H} \%$ 


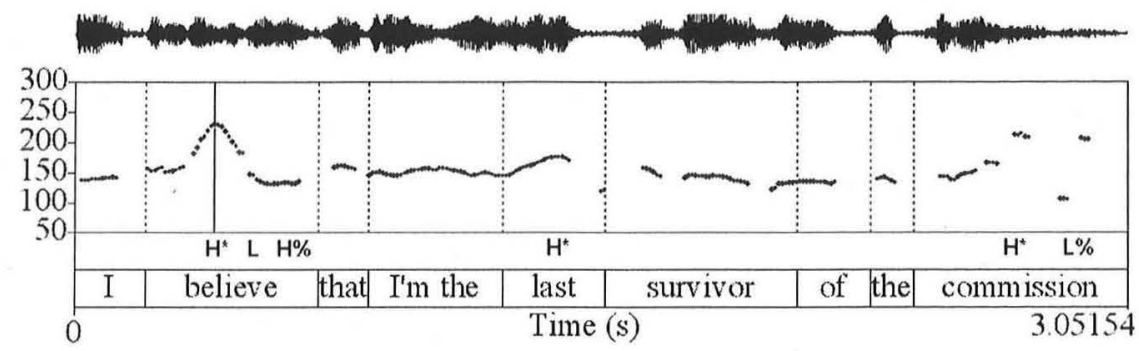

Figure 3. Prosodic separation of [PRN V]: that in following domain

Example (19), plotted in Figure 4, represents pattern (16)b2): I believe that is phrased separately as a unit with the nuclear pitch accent falling on the verb. The relevant local pitch peak associated with the second syllable of believe is indicated by the vertical solid line and the annotation $\mathrm{H}^{*}$ on the tonal tier. From the local peak the F0 contour falls and rises again towards the high boundary tone. Along with $\mathrm{H} \%$, the domain boundary is clearly marked by a non-hesitational pause of approximately $500 \mathrm{~ms}$ after that and by a step-down in pitch on we as the first (unstressed) syllable of the next domain. The pitch peak on need is reset with respect to the one on I believe, and declination applies across each of the two domains.

(19) a. and I believe that we need to hear that voice again moderation not just as compromise as wishy-washy liberalism or what have you but as absolutely fundamental religious principle (ICE-GB: slb-047 \#115)

b. [and $I$ be lieve that] [we...

$\mathrm{H}^{*} \mathrm{~L}, \quad \mathrm{H} \%$

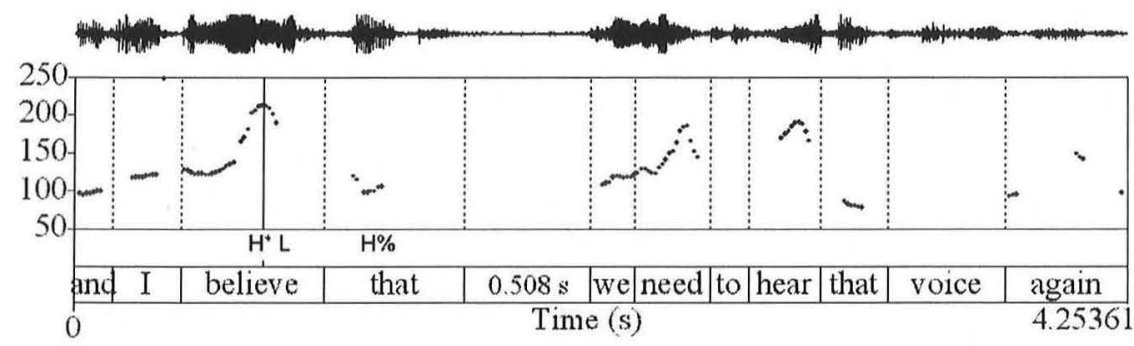

Figure 4. Prosodic separation of [PRN V that]

Example (20), plotted in Figure 5, represents pattern (16)b3): the sequence I think that the problem of faith forms one intonation domain with a continuous, downstepped sequence of two prenuclear (on think and pro-) and one nuclear (on faith) pitch accent. Thus, the prenuclear prominence in the target sequence falls on the verb. There is no reason to assume a boundary that divides the intonation domain. For example, there is no pitch discontinuity or pause, and declination applies across the whole domain. 
(20) a. [... I think that the problem of faith very often presents itself as an individual problem <,> (ICE-GB: s1b-028 \#104)

b. [I think that the problem of faith] [...]
$\mathrm{H}^{*}$
$! \mathrm{H}^{*}$
! H*L L \%

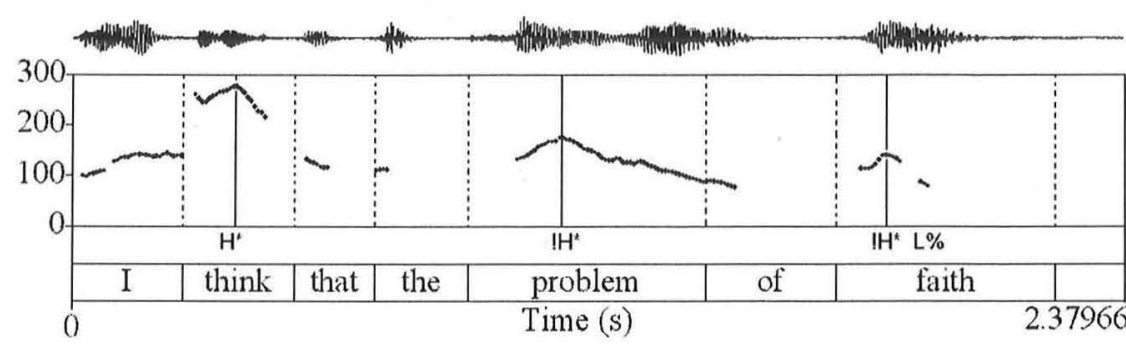

Figure 5. Integration as head; prenuclear pitch accent on the verb

Finally, (21), Figure 6, illustrates pattern (16)c), i.e. the unstressed target sequence integrated as prehead. Specifically, the string I think that these democratic ideals forms one intonation domain. The target sequence I think that is unstressed and integrated in this domain as a prehead. The first (prenuclear) prominence falls on the demonstrative these following that, while the nuclear sequence of a downstepped $\mathrm{H}^{*} \mathrm{~L}$ pitch accent followed by a high boundary tone is associated with the second syllable of ideals and the end of the domain.

(21) a. I think that these democratic ideals still have to be achieved in Britain and I hope to show in this programme that this can't be achieved until Britain becomes a republic (ICE-GB: $\mathrm{s} 2 \mathrm{~b}-032$ \#)

b. [I think that these democratic i deals] [...]

$\mathrm{H}^{*}$ $! \mathrm{H}^{*} \mathrm{~L} H \%$

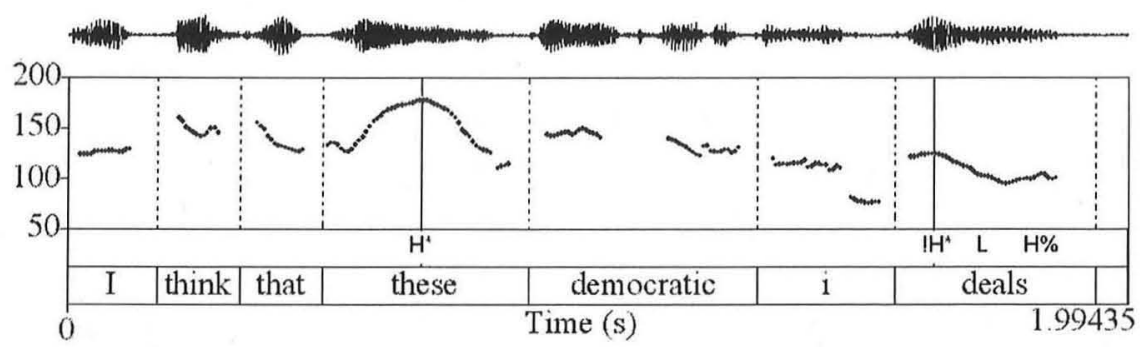

Figure 6. Integration as prehead (unstressed)

The observed patterns are distributed across our data as summarised in Table 1. More than half our data (47 out of 80 target sequences) came with an accent on the verb (pattern (16)b)). Next in frequency is pattern (16)a): 19 target sequences had an accent on the pronoun, while 14 target sequences were unstressed. Regarding 
Table 1. Distribution of prosodic patterns across target verbs

\begin{tabular}{|c|c|c|c|c|c|c|c|}
\hline \multirow{2}{*}{$\begin{array}{l}\text { public } \\
\text { domain }\end{array}$} & \multicolumn{2}{|c|}{ PRN prominent } & \multicolumn{3}{|c|}{$\mathrm{V}$ prominent } & \multirow{2}{*}{\begin{tabular}{|l}
\multicolumn{1}{|c}{$\begin{array}{c}\text { Un } \\
\text { stressed }\end{array}$} \\
prosodic \\
integra \\
tion \\
{$[$ PRN V } \\
(that $). .]$.
\end{tabular}} & \multirow[t]{2}{*}{ Overall } \\
\hline & $\begin{array}{l}\text { prosodic } \\
\text { separation } \\
{[\text { PRN V] }} \\
{[(\text { that }) . . .]}\end{array}$ & $\begin{array}{l}\text { prosodic } \\
\text { integra } \\
\text { tion } \\
{[\text { PRN V }} \\
(\text { that }) . . .]\end{array}$ & $\begin{array}{l}\text { prosodic } \\
\text { separa } \\
\text { tion } \\
{[\mathrm{PRN} V]} \\
{[(\text { that })} \\
\ldots]\end{array}$ & $\begin{array}{l}\text { prosodic } \\
\text { separa } \\
\text { tion } \\
{[\text { PRN }} \\
\text { V that }] \\
{[\ldots]}\end{array}$ & $\begin{array}{l}\text { prosodic } \\
\text { integra } \\
\text { tion } \\
{[\text { PRN V }} \\
\text { (that) ...] }\end{array}$ & & \\
\hline $\begin{array}{l}\text { I believe } \\
\text { that }\end{array}$ & 3 & 3 & 8 & 2 & 2 & 2 & 20 \\
\hline I believe $\varnothing$ & 1 & 2 & 0 & 0 & 14 & 3 & 20 \\
\hline $\begin{array}{l}\text { I think } \\
\text { that }\end{array}$ & 1 & 4 & 0 & 1 & 12 & 2 & 20 \\
\hline I think Ø & 0 & 5 & 0 & 0 & 8 & 7 & 20 \\
\hline \multirow[t]{2}{*}{ Overall } & 5 & 14 & 8 & 3 & 36 & 14 & \multirow[t]{2}{*}{80} \\
\hline & \multicolumn{2}{|c|}{19} & \multicolumn{3}{|c|}{47} & 14 & \\
\hline
\end{tabular}

intonational phrasing, only 16 out of 80 target items were phrased in their own domain, i.e. were prosodically separate, among them 13 I believe that (10 with accent on the verb), 2 I think that, and 1 I believe $\emptyset$. While integration is generally more frequent than separation, I believe that is phrased separately more often than not, and also more often than all three other patterns. In our data, I think that patterns very similarly to I believe $\emptyset$. I think $\emptyset$, on the other hand, is unstressed more often than any other combination, and it is never phrased in its own domain.

These findings, including the differences between the two verbs and instances with and without that, will be further discussed in Section 4. First, we will relate the observed prosodic patterns to their interpretation.

\subsection{Relating prosody and interpretation}

Remember from Section 2.2 that it is impossible to identify the use of $I$ think/ believe (that) as $\mathrm{MC}, \mathrm{CC}$ or DM on the basis of the prosody of syntactically unambiguous MCs, CCs and DMs because syntactically unambiguous MCs, CCs and DMs do not have a unique and unambiguous prosody. In this section, we therefore aim at establishing a relation between the observed prosodic patterns and their interpretation and use in discourse. Note that, in order to follow the discussion below, it is important to keep in mind the exact location of the accent, if present, as specified for each example. We will inspect the discourse contexts of a number of representative examples. Based on the literature as reported above, we will identify MC, CC 
and DM uses. In particular, we will argue along the lines of established criteria such as Boye \& Harder's (2007) 'addressability' of MCs, Kearns' (2007) criteria for discourse status based on Urmson (1952, 1963), and Diessel \& Tomasello's (2001) distinction, all discussed in Section 1 above. In addition, we will base our discussion on Allerton \& Cruttenden's (1974) observations for initial S-adverbials (see Section 2.2 above), which are, according to much previous literature, similar in function to CCs. Target sequences and their extended discourse contexts were drawn from the ICE-GB in order to allow for interpretation. In (22), (25), (27), (28), (30) and (31), utterances hosting the target sequences are printed in bold throughout.

Our first example, given in (22), is taken from a broadcast discussion among writers. Prosodically, it follows pattern (16)a1): The target sequence I believe is phrased separately with that following in the next domain; the accent is on the pronoun (cf. (23)). The discourse situation is such that the discussion focuses on one writer who "receives novels from the other side", i.e. she is being used by famous dead authors who write their novels through her. In the extract given in (22), the interviewer A asks the writer in question, B (Stella), how it all began. She spends some time telling her audience what has been happening since she first got involved in this on a gloomy rainy day during a holiday in Scarborough on the Yorkshire coast. Speaker $\mathrm{C}$ does not believe her. The interviewer then asks another novelist, Monica (D) for her view (see italicised utterance in (22)). Monica offers her opinion (see bold-printed target sequence). Crucially, the main proposition is the assertion of Monica's opinion (see Diessel \& Tomasello's 2001 'assertive' use), while the second proposition, that anything is possible, is subordinated. Therefore, I believe in this case is an expression of true belief, not a comment on the proposition expressed by what follows. $I$ believe in this context thus functions as an assertive MC. The tests in (24) show that the MC is 'addressable' in Boye \& Harder's (2007) sense. We can, for example, add a short question that relates to I believe (crucially with accent on the pronoun; see (24)a)), while a tag relating to the rest of the sentence is odd (see (24)b) and keep accent placement on the pronoun in mind). Furthermore, the utterance can be continued employing a proform, do, which refers to I believe... (see (24)c)).

(22) ICE-GB: s1b-026 \#1-260 (target: \#234)

(Broadcast discussion: BBC 4, Midweek with Libby Purves, 15 May 1991)

[...]

A: At this at this point uh we ought to bring in Stella Horrocks to the tune of haunting weird music

A: Imagine it please

A: Uhm she receives novels from the other side

$[\ldots]$ 


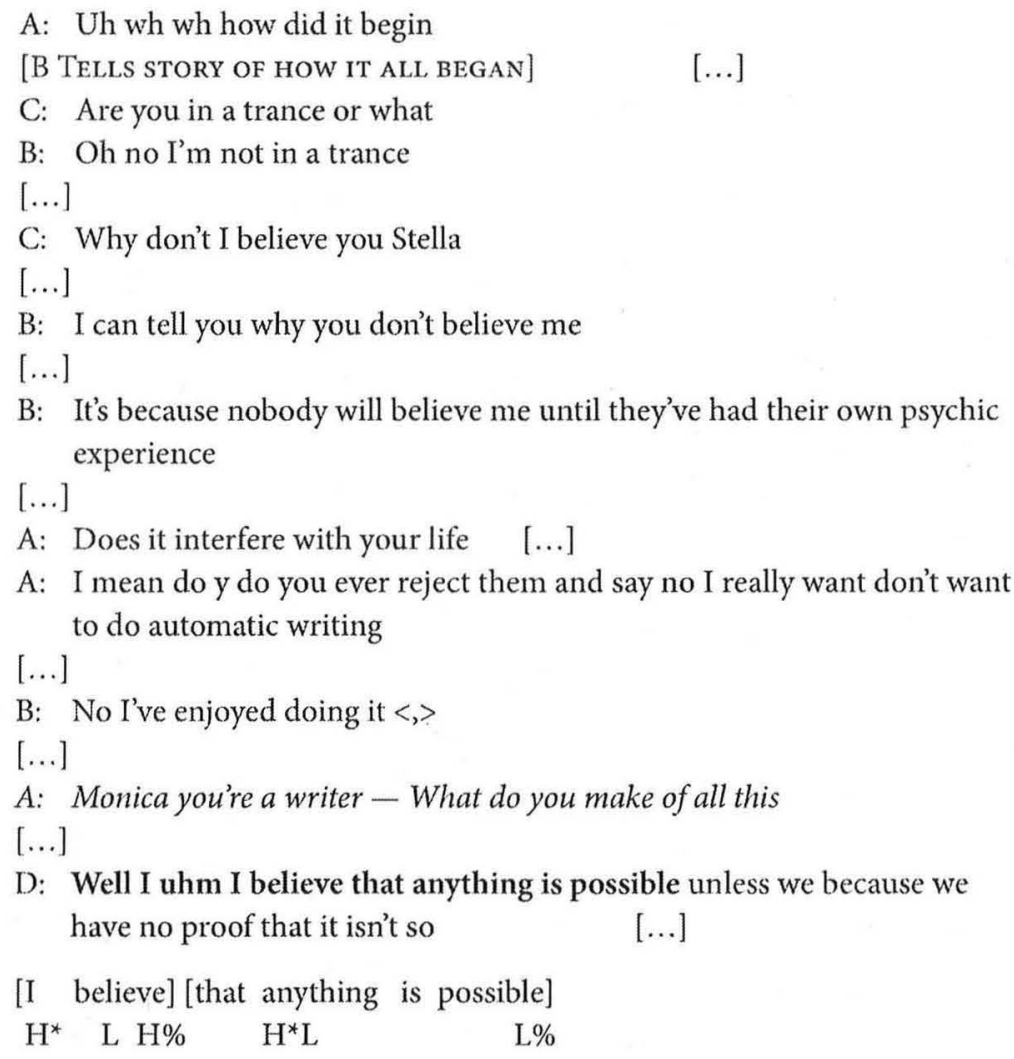

(24) a. I believe that anything is possible, don't you?

b. ??I believe that anything is possible, isn't it?

c. I believe that anything is possible, and I will do so until someone proves the opposite.

In (25), from a broadcast discussion on debates and contests within UK politics, the bold-printed line serves as an example of $I$ think $\emptyset$ which is integrated as an intonational head with a prenuclear accent on the pronoun $I$. It thus follows pattern (16)a2) (see the annotation in (26)). As can be seen from the context (see italicised lines), the target speaker (D: Heather Couper) has explicitly been asked for her opinion. As she replies to this question, giving her view on the topic, she places an accent on the pronoun $I$ rather than the verb think, expressing her own attitude. She then continues explaining her view to the audience. As in the previous example, there can be no doubt that this is an example of the expression of real speaker attitude, thus providing an example of 'assertive' use of I think. Omitting the target sequence would be odd since the fact that this is the speaker's view is the 
main proposition, explicitly elicited by the questions "what's your view?". It would be possible to replace I think by It is my view that ..., but not with, for example, probably, presumably or certainly. Also, think allows for adverbial modification, e.g. I actually think or I really think, indicating propositional as opposed to grammatical status (see also Boye \& Harder 2007:580). Moreover, one could easily reply "Do you (really think so)?", i.e. use a follow-up question picking up on $I$ think rather than the rest of the utterance. Thus, I think qualifies as a main clause in this context.

(25) ICE-GB: s1b-024 \#17-30 (target: \#28)

(Broadcast discussion: BBC 4, Start the Week, 12 Nov 1990; 4 speakers A-D, $A=$ interviewer; $D=$ Heather Couper)

$[\ldots]$

A: You speak here in in as a double capacity because you're not only legal man and Rumpole man but you're Henley man $<$, >

C: Well actually I I haven't got the uh the uh joy and entertainment of being one of Mr Heseltine's constituents because I live just across the corner in Buckinghamshire

A: So whatever you're just that little bit of an outsider Mortimer

C: I'm just a bit of that <laughter $>$

A: You get away with it yet again $<,>$

A: Heather Couper what's your view of the uh of of the upfront fighting if we can use that clumsy awkward

A: Don't forget it is Monday morning

D: <laughter> If I can partly misquote John and say yes indeed it adds to the gaiety of the country

D: That's not the appropriate word at this time of the morning but still

D: I think it's all jolly good fun

D: In fact I went along to the House of Commons to watch an adjournment debate on Wednesday night last week and uh I loved the way everybody postures and poses

D: I it's like ballet really in a way

(26) [I think it's all jolly good fun.]

$\mathrm{H}^{*}$

$! \mathrm{H}^{*} \mathrm{~L} \%$

These two examples suggest a direct relation between accent placement on the pronoun and use as an assertive $\mathrm{MC}$, regardless of whether the target sequence is prosodically separate or integrated.

Next, we will present data suggesting a relation between the target sequence functioning as a CC and accent placement on the verb, regardless of whether it is a nuclear accent (prosodic separation) or a prenuclear accent (prosodic integration). 
Example (18)/Figure 3 above patterns according to (16)b1), i.e. there is a nuclear accent on the verb and the phrasing is such that that phrases with following material. The discourse context of this particular example is given in (27). The example is taken from a broadcast talk. The speaker tells the audience about his work as a member of a royal commission on common lands, which did its work a long time ago. The commission did not succeed in securing common lands for the public, which is, however, still a matter of public interest. The target sequence could easily be replaced with, for example, the 'likelihood adverbial' (Allerton \& Cruttenden 1974) presumably, yielding: Presumably, I'm the last survivor of the commission. The focus is not on the speaker's belief, but on the suspicion that he alone is still around after all these years, and on the contrast with the following utterance: he may be the only survivor of the former committee, but he is not the only person supporting the ideas of that committee. The nuclear fall-rise realised on believe corresponds to one of the patterns observed for likelihood adverbials by Allerton \& Cruttenden (1974:15f). They identify the relevant pattern (fall-rise, separate intonation group) for dubitative message-oriented adverbials such as presumably used with a not previously mentioned, 'new' sentence, i.e. exactly the context we find here.

(27) ICE-GB: s2b-025 \#60-128 (target: \#127)

(Broadcast talk; BBC 4, For He Is An Englishman, 5 February 1991);

[...]

A: Another was that in nineteen fifty-five I was asked to serve on the Royal Commission on Common Lands under Sir Ivor Jennings <,>

$[\ldots]$

A: One of the mass demands much voiced by the Labour Party was the use of the countryside for recreation $<,>$

$[\ldots]$

A: These lands over a million acres of them were derelict because everybody had forgotten who had what rights or duties over them $\langle$, >

[Long Story About the Cumbersome Work of the Commission] [...]

A: After three years George presented the draft report for our approval $<$, >

A: We had a friendly press conference and dispersed $<$, $>$

A: None of us were sanguine

A: we knew too much about the government regime for that $<,>$ and when seven years later the Commons Registration Act was passed ostensibly on the basis of our report $<,>$ the government of the day got it wrong $<,>>$

A: Would you like to know how <,>

A: Commons are our last uncommitted land resource $<,>$

A: We devised ways of ensuring that they remained uncommitted yet put to environmentally-satisfying use $<$, > 
A: These ways were left out of the act with the result that astute gravel merchants and estate developers exploit loopholes in the law to discommon and ravage $<,>$

A: I believe that I'm the last survivor of the commission $<$, $>$

A: I trust that I'm not a lone voice $<$,

(28) provides the discourse context for an example of I believe that phrasing together as a separate domain. In all our instances of this prosodic pattern the accent is on the verb (think or believe), while the pronoun is unstressed. It thus follows pattern (16)b2). The fact that that joins the prosodic domain of I believe/I think rather than that of the following clause suggests routinisation of the target sequence: that forms a unit with the pronoun and verb. In this particular example, taken from a broadcast discussion on the countryside and its role in today's urban society, I believe that could easily be omitted or replaced by undoubtedly. I believe that is not doubtful in this context. Rather, it represents a likely estimation of the number of people enjoying the countryside and thus strengthens the force of the proposition. According to Allerton \& Cruttenden (1974:16), indubitative likelihood adverbials may be prosodically separate with either a fall or fall-rise. The present example is realised with a fall. The main proposition is expressed by the rest of the utterance, namely that quite a large percentage of the population like to go to the countryside regularly. A possible tag here would be "Don't they (like to ...)?" rather than "Don't you (believe that ...)?" Given this interpretation and the parallels in prosodic behaviour with likelihood adverbials we interpret this occurrence of $I$ think that as a CC.

(28) ICE-GB: s1b-037 \#26-30 (target: \#29)

(Broadcast discussion; BBC 3, Issues, 10 November 1990; 4 speakers overall);

D: Uh when I go home at the weekends it's not just going home to the farm which is a business

D: it's going home to something uh which is much deeper than that

D: It sort of revives me every week

D: And uh although we are largely an urban society uh $\mathrm{I}$ believe that over eighty per cent of the population like to get out into the countryside uh at least once a month

D: So it's it's much more than uh it's much more reality than myth even to an urban population

(29) [I believe that] [over eighty per cent] [...] $\mathrm{H}^{*} \quad \mathrm{~L} \% \quad \mathrm{H}^{*} \mathrm{~L} \%$

The example in (19) above behaves similarly in that the target sequence also functions as a comment on what follows rather than expressing a proposition on its 
own. It is taken from a broadcast interview on religion, in the target passage specifically on religious moderation vs. extremism. The main proposition is that the voice promoting religious moderation is needed once again. I believe that expresses the speaker's stance such that he is certain/it is clear that this voice is needed in society. This is once again reminiscent of indubitative likelihood adverbials as described by Allerton \& Cruttenden (1974: 16; clearly, definitely, certainly). Figure 4 shows prosodic separation for I believe that in this example with a nuclear fall-rise associated with the verb, i.e. the same pattern typically observed by Allerton \& Cruttenden (1974) for indubitative likelihood adverbials.

In contrast to target sequences integrated as heads with accent on the pronoun, which function as MCs (see the discussion of (25) above), integrated I think/ believe (that) as head with accent on the verb (pattern (16)b3)) is interpreted as a CC, like the other two patterns with accent on the verb. The discourse in (30) serves as an example. It provides the context for the example in (20), plotted in Figure 5. This discussion, broadcast on BBC 4, is entitled 'The Persistence of Faith'. 'Faith' and 'religion' are the central topics of a conversation among five speakers. The extract in (30) starts well into the discourse and finishes shortly before the end of the discussion. The main proposition of the bold-printed target utterance is that the "problem of faith" has nothing to do with subscribing to a particular moral framework or 'tradition', but is a matter of individual articles of faith. The speaker elaborates on how it is an individual problem, i.e. what the specific questions are that individuals have to deal with. A tag question relating to this would most likely not address I think that but instead the remaining clause: "Does it (present itself)?" rather than "Do you (think that ...)?".

(30) ICE-GB: s1b-028 \#100-109 (target: \#104)

(Broadcast discussion; BBC 4, The Persistence of Faith, 27 January 1991);

$[\ldots]$

B: Let let me give you an example if

C: II I <,> before you do <,> I I I think there wh some of us are in great difficulty here

C: and i perhaps Mrs Harrison may be too <, >

C: You don't do you want us to $<,>$ think of faith as a synonym for tradition $<,>$

C: Uh when at least among uh Christians uhm uh uh modern contemporary Christians I think that the problem of faith very often presents itself as an individual problem <,>

C: Can I believe in the Trinity

C: Do I believe in the historicity of Jesus

C: Do I believe this or that of the Thirty-Nine Articles of the Church of England or whatever 
$\mathrm{C}$ : And these present themselves to children and grown people as very very very serious personal difficulties while at the same times the the same time those very same people may be fully subscribed to the tradition of a certain morality a set of uh ways of behaving that ha ha have their authority from time immemorial as well as from ordinary reason

C: There's a kind of split mind at work there

$[\ldots]$

Finally, example (31) is one where the target sequence $I$ think functions as a discourse marker and is prosodically realised as an unstressed prehead (see pattern (16)c)). The extract is from a broadcast discussion on whether or not to allow women to become members of an all-male institution: MCC (Marylebone Cricket Club), "the greatest cricket club in the world". Speaker A is the interviewer, speaker $B$ is Rachael (Heyhoe-Flint), who would like to become a member, and speaker C is Wilfred Wooller, who has voted against female membership. The relevant utterance is crucially not about what the speaker thinks, what her opinion is, but it is about the contrast between those women who take cricket seriously (and are yet not allowed to become members of the cricket club), and some men who are allowed in but are club members for reasons other than cricket. I think introduces this contrast. It can be interpreted to function as a politeness marker: Rachael is trying to make her point in a polite way while sitting through a misogynous and rather offensive discussion. This instance of $I$ think can thus be seen to have a mitigating function. A possible (agreeing) reply would be "Yes, there are", rather than "So do I", i.e. what is addressable is the content of the clause following I think. This discourse use of $I$ think goes along with prosodic integration and the lack of prosodic prominence. Recall from Section 2.2 that for medial and final CCs, utterances serving discourse functions have also been found to be integrated and unstressed.

(31) ICE-GB: s1b-021 \#1-56 (target: \#56)

(Broadcast discussion; BBC 4, Sport on Four, 27 April 1991);

A: So with no existing rules to specify that it is an all-male club the Committee decided to throw the issue open to the members

A: It'll need a two thirds majority to see it through

A: Now the ex-Glamorgan captain and former test selector Wilfred Wooller has already voted against it

A: And so we thought we'd bring Wilfred and Rachel together

[...]

A: Why for instance is Rachel so keen to break into this peculiarly male institution 
B: It's basically that I think perhaps immodestly that I've become associated with cricket over the years and I would love to be a member of the $[\ldots]$ greatest cricket club in the world and it's it's just as simple as that

A: Wilfred Wooller in Cardiff

$[\ldots]$

C: I voted against this in my paper last week which will go through to the MCC

C: It's one of the few havens $<,>$ left for men in my view

$[\ldots]$

C: and I've nothing against them the ladies except that it's very pleasant to go into a man's club and don't have to worry about what you are saying what you are doing and how you're doing it and what you know what's going on and being distracted by some attractive young girl round the corner <,>

C: You've got to concentrate on cricket uh

B: I think a lot of men at uh cricket they don't concentrate

$[\ldots]$

B: do you no notice the sort of clinking of the glasses in incredibly particularly in the hospitality boxes at the the major test match grounds

B: I think there are many women who probably would take it far more seriously than some of the men who are only there for the $<_{\text {, }}>$ <unclear-word >

$[\ldots]$

Based on the discussion of these examples, we suggest a relation between accent placement and the discourse status of the target sequence as summarised in (32): ${ }^{11}$

(32) Relation between prosody and interpretation:

a. If only the pronoun is prominent, the target sequence functions as an assertive propositional main clause (MC).

b. If only the verb is prominent, the target sequence, whether integrated or separate, functions as a comment clause (CC).

c. Integrated, unstressed $I$ verb (that) functions as a discourse marker (DM).

\section{Discussion}

As these results show, initial I think (that) and $I$ believe (that) can function as $\mathrm{MC}$, CC or DM. In this section, we will first address the patterns summarised in (32) in turn, before discussing some further issues related to the results. 
The first generalisation is that if only the pronoun is prominent, the target sequence functions as a propositional MC. This holds independently of the phrasing, i.e. whether the target sequence is phrased in a separate intonation domain or whether it joins the following domain, and, consequently, it holds true for nuclear and prenuclear accents on the target pronoun. ${ }^{12}$ This finding makes sense under the view of $\mathrm{MC}$ use as the lexical one expressing real attitude/ true belief on the part of the speaker. By deaccenting the verb, the speaker treats the verb as information that is cognitively salient or 'given', and thus sets up a contrast between the views of the speaker and what others may think or believe. This use is consistent with Diessel \& Tomasello's (2001) account of "assertive" use, in which "the [complement-taking verb] clause expresses the main proposition of the whole utterance" (Diessel \& Tomasello's 2001: 108), and with Boye \& Harder's (2007) "lexical variant", which "expresses the main point of the utterance" (Boye \& Harder's 2007:584).

Second, if the verb is prominent with a nuclear or pre-nuclear accent and the pronoun is unstressed, the target sequence functions as a CC. Three different patterns were discussed (see (16)b)). The target sequence may be integrated as a head, or it may be phrased separately such that that joins the pronoun-verb sequence or joins the following domain. While integration as head is very frequent, the separation of pronoun/verb from that has been observed for I believe that only. The tonal pattern is typically a fall or a fall-rise. Prosodic separation with a nuclear fall or fall-rise corresponds to the pattern of initial message-oriented adverbials, in particular to the subclass of likelihood adverbials such as possibly, presumably, probably, clearly, definitely, certainly (Allerton \& Cruttenden 1974). If that joins the pronoun-verb sequence in its intonational domain, the prosodic unit corresponds to a conventionalised, routinised unit of the whole sequence: that is not seen as a conjunction introducing a subordinated clause (i.e. syntactic complementiser), but is part of the same processing unit as I think/I believe. This is reminiscent of what Bybee \& Scheibman (1999), referring to Haiman (1994), call 'natural chunking': elements that are frequently used together tighten their phonological and semantic bonds and their constituency and become "automated as a processing unit" (Bybee \& Scheibman 1999:577). Prosodic separation is also consistent with Aijmer's (1997) claim that speech act adverbials typically occupy a separate tone unit. If on the other hand the target sequence is prosodically integrated and the accent on the verb is prenuclear, it is, in our data, usually a high peak, which is the first in a sequence of downstepped ones (see Figure 5). This corresponds to one of the patterns Allerton \& Cruttenden (1974) found for sentence initial messageoriented adverbials, which occur "as part of the pre-nuclear tune" (see Section 2.2 above). The occurrence of both prosodic separation and integration with the same $\mathrm{CC}$ function is consistent with frequency-based accounts of grammaticalisation. 
Croft (2000), for example, suggests that changes of form and meaning "tend to occur together, and all in the same direction, essentially towards reduction and tighter integration of form (to the point of fusion or elimination), and with respect to function from more 'concrete' to more 'abstract'" (Croft 2000:62). This would suggest that prosodic integration is simply at a point further along the grammaticalisation path than separation.

Regarding phrasing, note that the pattern [PRN verb that] occurs only with the accent on the verb. There are no cases in our data set with this phrasing and accent on the pronoun. Phrasing of that with the verb-pronoun sequence is possible only under performative, grammaticalised usage. This makes sense because if the accent is on the pronoun the target sequence is interpreted as an assertive main clause. In the case of MC, that must syntactically be seen as a complementiser (conjunction) introducing the embedded clause. The routinised, grammaticalised usage of the pronoun-verb-that sequence, at the same time, is therefore impossible.

Finally, we claim that the prosodically integrated, unstressed $I$ verb (that) sequence has a discoursal function. The loss of prosodic prominence is typical of the process of grammaticalisation, and correlates with loss of semantic value, or, in Croft's terms, a change from concrete to abstract meaning. The fact that the unstressed cases are also prosodically integrated is consistent with the notion that reduction (here loss of accent) and integration (here in terms of prosodic structure) co-occur. The sequence with this prosodic pattern thus appears to have lost its propositional value and to fulfil an interpersonal function, such as, for example, hedging for politeness purposes. This finding is also consistent with Dehé \& Wichmann's (to appear) results for medial and final CCs, for which they identify a relation between prosodic integration and lack of prominence on the one hand and discoursal or interactional function on the other hand (see Section 2.2 above). Notice also that the absence of stress has not been found by Allerton \& Cruttenden (1974) for message-oriented adverbials. This lends further support to the assumption that unstressed $I$ think (that) and $I$ believe (that) have been further grammaticalised to function as a discourse marker. This pattern has been found for all four target combinations, but is most frequent with I think $\emptyset$.

To summarise: in the propositional (assertive) MC use, initial I think/believe (that) come with a nuclear (prosodic separation) or prenuclear (prosodic integration) accent on the pronoun, which is due to the expression of true speaker attitude, opinion or belief. In their performative CC use, the accent is on the verb. Again, the sequence may be either prosodically separated or integrated as the head. If the target sequence is unstressed and integrated as a prehead, it is used/ interpreted as a discourse marker, while losing even more semantic content. The findings are consistent with those of Kärkkäinen (2003) who claims that $I$ think is 
grammaticalising into a discourse organising function, with a concomitant attrition of form including a lack of stress and phonetic reduction.

In its propositional use, the verb functions as an argument-taking predicate. Semantically, the internal argument of the verb incorporates the essence/content of the speaker's belief, opinion or attitude - it is what the speaker believes/thinks. In the performative use, on the other hand, the target sequence functions like a performative speech act adverb (Diessel \& Tomasello 2001). This is also known from Relevance Theory (RT; Sperber \& Wilson 1986/1995) as 'procedural meaning' (Blakemore 1987, 2002, 2005): expressions such as those in focus here do "not encode a constituent of a conceptual representation (or even indicate a concept), but guide the comprehension process" (Blakemore 2002:90f).

If we consider only the syntagmatic properties of our data, we see from the results summarised in Table 1, Section 3.1 that there is a clear difference between $I$ believe that and all other combinations investigated here. In particular, I believe in I believe that is phrased separately more often than any of the other target items. On the other hand, I think $\emptyset$ occurs as an unstressed prehead more often than any of the other combinations. These differences reflect the semantic properties of think and believe as well as their relative frequencies. Believe is both more formal and less frequent than think. According to Dor (2005:352), for instance, some predicates, among them believe, entail "a much stronger truth claim" than related predicates. In our context: believe entails a stronger truth claim than think. As regards frequency, it has been argued repeatedly in the literature that the frequency of an element in question is a key factor in its grammaticalisation from a more transparent to a more grammatical meaning (see Hopper \& Traugott 2003 and references given there). I think $\emptyset$ is by far the most frequent of the four target sequences, including $I$ think that. This is in line with findings reported elsewhere in the literature, e.g. Biber et al (1999:680) who note that "[i]n conversation, the omission of that is the norm, while the retention of that is exceptional". Due to its frequency and relative semantic emptiness, think lends itself, in general, more readily to use as a comment clause or discourse marker. It is therefore not surprising that 15 out of 20 instances of I think $\emptyset$ were either CCs or DMs, and that the sequence remains unstressed more often than any of the other sequences.

A pattern that deserves further attention is the prosodically separate MC: pattern (32)a) with pronoun and verb phrased together in a separate domain. Following prosodic theory, in particular constraints such as edge alignment or Wrap, a boundary is not predicted in the position following the verb (see Section 2.2 above). However, previous work has shown that speakers have options for the intonational phrasing of a given syntactic structure (see Nespor \& Vogel 1986, Shattuck-Hufnagel \& Turk 1996 among others). In our case, the speaker has a choice between separating the target sequence from the rest of the sentence by 
a domain boundary, and phrasing the whole sentence in one domain. Which of the variants the speaker selects, depends on extra-syntactic factors such as length, speech rate, style of speech and semantic considerations (see, e.g. Nespor \& Vogel 1986: 193ff). Particularly relevant in the present context is the observation that a long IP may be restructured such that a boundary may be inserted between a main verb and its clausal argument, e.g. between a main verb and a that-clause (Nespor \& Vogel 1986: 198f). It follows that while edge alignment and Wrap do not predict a boundary in this position, a prosodic boundary of the kind optionally found here between think/believe and the that-clause is not uncommon.

From a syntactic perspective, it is not immediately obvious why that is still possible under the initial CC analysis. If initial I think, I believe are not main clauses, then the rest of the sentence is the main clause, and main clauses in English are not normally introduced by that. The apparent complementiser (conjunction) should thus be impossible. There is more than one answer to this question. First, we argue that that in these cases is not a conjunction/complementiser introducing the clause following think/ believe. Rather, I think that and I believe that have become routinised and that is a part of the initial CC. These results support Aijmer's (1997) view that the mere presence or absence of that is not a key factor in the decision of whether initial I think functions as MC or CC. Rather, prosodic evidence suggests that there can be both MC and CC and even DM with and without that. This goes against Thompson \& Mulac (1991a, b) who see initial I verb Ø invariably as a modifier. It supports, however, Kearns' (2007) view that the target sequence in initial position may be a modifier even when that is present. It also supports Dor (2005), who claims that clauses with and without that do not differ in terms of truth condition. For predicates that allow both structural options speakers have a choice, but this choice does not make a difference in the semantic interpretation of the embedded clause.

Second, from a historical perspective, that may have, in these cases, developed not from a conjunction introducing a that-complement, but, for example, from a demonstrative pronoun functioning as the object of think/believe (e.g. Traugott 1992: 234-241). If so, the routinisation of the sequence I think/believe that would be accounted for even more readily. See also Brinton (1996:244-253) and Fischer (2007:297-308) for discussion of the origin of that in this context. These studies show that Thompson \& Mulac's (1991) main clause hypothesis, which holds that sentence-initial CCs "are grammaticized forms of subjects and verbs introducing complement clauses" starting with that (Thompson \& Mulac 1991:317), and which is entirely based on the frequency of occurrence in data from present day English, cannot be maintained in the light of historical evidence (Brinton 1996:244-253; 2008; Fischer 2007:297-308). Instead, other paths of development must also be considered. Note that this does not cast any doubt on the assumption that there 
are more or less propositional or more or less grammaticalised uses of initial $I$ think/believe (that) in present-day English, but only that there may not be a direct historical development from MC I think/believe to initial CC I think/believe.

Third, it has already been noted that there are non-syntactic constraints on the inclusion or omission of that. Dor (2005) suggests, for example, that there are contextual constraints on the inclusion or omission of that, while Biber et al (1999:680-682) include register factors and discourse factors. To these we add the possibility of rhythmic constraints. The presence of that in a sentence means the presence of an unstressed syllable. Consider the example in (33), repeated from (20), Figure 5. As is shown in (33), the absence of that would create an irregular pattern such that the first two stresses would be separated by one unstressed syllable, the last two stresses by two unstressed syllables; the presence of that results in a more regular (dactylic) rhythmic pattern. The example in (34) exemplifies the case of the absence of that compatible with the regular rhythmic pattern. An even more straightforward example is provided by the poem in (35), in which that is used only in lines 1 and 3 to allow for a regular pattern of two unstressed syllables between the initial stressed syllable know and the next stressed syllable (love, care, see and there in lines 1-4, respectively). This example also shows that speakers can 'play' with the absence vs. presence of that and that the hierarchical relation between the apparent main verb and the apparent subclause is secondary in the decision of whether or not that is used.

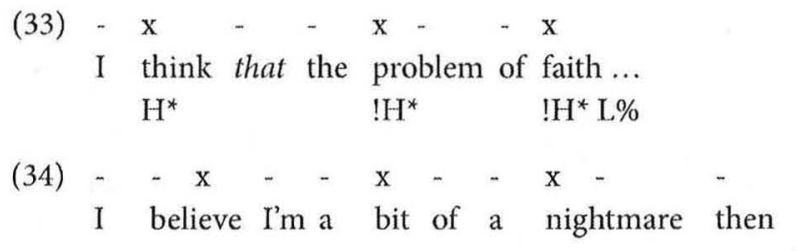

(ICE-GB: s1a-038 \#256)

(35) Know
1 Know that $\mathrm{I}$ love you
2 Know I don't care
3 Know that I see you
4 Know I'm not there

$\left(\right.$ Nick Drake) ${ }^{13}$

We conclude that the presence or absence of that does not affect the way in which we analyse the function of $I$ verb (that). The prosodic realization (paradigmatic - in terms of prominence placement; syntagmatic - whether a separate IP or integrated into a larger IP), on the other hand, reflects discourse functions such that initial I believe (that) and I think (that) can function as MC, CC and as DM. 
Another syntactic aspect of the analysis suggested here based on prosodic evidence relates to the category and syntactic status of initial CCs. In the literature, it has often been assumed that despite the shift in meaning and the grammaticalised use of the target expression as adverbial, a reanalysis of the syntactic structure is not necessary (e.g. Kearns 2007; Diessel \& Tomasello 2001; Boye \& Harder 2007). Instead, these authors permit a hybrid analysis and allow for the target expression to be an adverbial functionally, but a MC syntactically. In particular, Boye \& Harder (2007) have a category "secondary lexical", which means that a particular instance of the target expression has predicate force and selects arguments (their 'lexical'), and at the same time "has only a concomitant function in relation to the rest of the utterance" (Boye \& Harder 2007: 584; their 'secondary'). Similarly, Diessel \& Tomasello (2001:108) allow for the clause introduced by (that) to be "formally subordinated but conceptually non-embedded" in the matrix clause $I$ think etc. We suggest that prosodic realisation provides the basis for the rejection of this notion of hybridity. The apparent ambiguity observed by Boye \& Harder (2007) is based entirely on the morphology, which is indeed ambiguous in many cases, even in context. However, while the variants may not be "morphologically distinguishable" (Boye \& Harder 2007:582), they are most certainly prosodically distinguishable. The formal prosodic distinctions we observe (in terms of prosodic prominence and phrasing) indicate that, from the speaker's perspective, there is no hybridity: the speaker's analysis is reflected in the prosody. If, for example, a target expression is prosodically marked as a CC, the speaker has chosen to analyse the following clause as the main proposition. I think/I believe can thus not simultaneously be analysed as a MC. This is not to say that a speaker might not realise a morphologically identical utterance on another occasion as a MC and subordinated complement clause. If the prosodic structure reflects a prior semantic and syntactic choice, then hybridity is a theoretical impossibility. ${ }^{14}$

In syntax, under the $\mathrm{MC}$ analysis, the 'complement clause' is merged with the verbal head (think or believe) as its argument, and the new syntactic element is then merged with the subject. If the target verb has no predicate status (and thus no argument-selecting property) and the pronoun-verb sequence functions as a grammaticalised unit, pronoun and verb will either have to be assumed to be lexicalised, or merge and form a syntactic object before merging with the rest of the clause. It has been observed elsewhere in research on grammaticalisation that certain instances of grammaticalisation lead to changes in category and constituent structure (see Hopper \& Traugott 2003 and references given there). The "cline of categoriality" in (36) is taken from Hopper \& Traugott (2003: 107).

(36) major category ( $>$ intermediate category) $>$ minor category 
While both verbs and nouns belong to the major categories, intermediate categories include adverbs. While in their MC use, think and believe are major categories, in their CC and DM uses they are not. It seems possible therefore that I think (that), I believe (that) and related expressions in their CC uses will have to be syntactically reanalysed as adverbials occurring in an adjoined adverbial position.

\section{Summary}

The results of the present study are essentially twofold. First, we have provided evidence supportive of the assumption that initial I think (that) and I believe (that) may function variously as a main clause, a comment clause, or as a discourse marker. The target expressions are on an interpretational cline from propositional to formulaic. Whether or not that is present is not a matter of MC, CC or DM use, but depends on a number of factors, among them several non-syntactic factors to which we have added the rhythmic pattern of the sentence. Second, our results show that while there is no single prosodic pattern that defines $\mathrm{MC}, \mathrm{CC}$ or DM, the use and interpretation of the target sequence is nevertheless reflected in its prosody and that prosody thus disambiguates between the individual meanings. While morphology and syntax often fail to draw a clear line between uses because identical forms serve different functions, these functions are disambiguated in speech by their prosodic realization.

\section{Notes}

* We would like to thank Karin Aijmer and Elizabeth Traugott and the audience at the New Reflections on Grammaticalization 4 Conference in Leuven in July 2008 for their discussion, as well as two anonymous reviewers and one associate editor at Studies in Language for their comments. The work presented was based on data from the International Corpus of English and made use of accompanying software. ICE-GB is coordinated by the Survey of English Usage, University College London. For more information, consult the following website: $<$ http://www. ucl.ac.uk/english usage/projects/ice gb/>.

1. We concentrate on English in this paper. However, the syntactic debate is not confined to English CCs. The related verb-initial construction in German, for example, has also been subject to controversial discussion along the same lines. See, e.g. Reis $(1995,2002)$ for the parenthetical analysis, Tappe (1981), Grewendorf (1988), Haider (1993) and Wagner (2004) for the extraction analysis. Kiziak's (2007) experimental study provides support for the parenthetical analysis sug gested by Reis $(1995,2002)$. Notice also that Schelfhout, Coppen \& Oostdijk (2004) argue for a parenthetical analysis for Dutch, and that Schneider $(2007 \mathrm{a}, \mathrm{b})$ refers to related elements in Romance as "reduced parenthetical clauses". 
2. Work in this spirit, which acknowledges similarities between adverbials and comment claus es, goes back at least to Urmson (1952) who likens comment clauses (parenthetical verbs in his terminology) to stage directions and argues that they function as mitigators which comment on the main proposition.

3. According to Quirk et al (1985:1113), (2)c) is not an exact paraphrase of (1)c) but they are closely related. While the $\mathrm{CC}$ in (1)c) has a hedging meaning, the main clause in (2)c) may have "a more definite meaning". Notice also that Quirk et al (1985:1113) suggest a "reversal of syntac tic roles", of "the relationship of subordination between the two clauses". This implies that (1)c) cannot have been derived from (2)c) by a syntactic movement operation, since movement does not alter the underlying relation between constituents (see Emonds's 1976 Structure Preserving Constraint).

4. For the purpose of this introduction, we will refer to the target verb as the matrix verb and the following clause as the embedded clause. In contrast with the present paper, the literature referred to in this paragraph is not restricted to the verbs think and believe, or to 1st person sg pronominal subjects, but deals with the optionality of the complementiser that in more general terms.

5. A reviewer notes that a tag containing you provides for a perfectly normal sentence in (4)b). As far as we can tell, it is true that it is possible, but only if the stress is on the first pronoun $I$ and also on you in the tag. In other words, it is possible under contrastive stress on the pronoun. This fits our claim to be developed below, that an accent on the pronoun means that it is used as main clause, while an accent on the verb does not.

6. But note that it would also be possible to argue that if it is an exact paraphrase, both the initial sequences and the medial and final counterparts are main clauses, which, if they are preceded by syntactic constituents, is syntactically possible (see the discussion in Dehé 2009:579 582).

7. Our argument presupposes that 'conveying the main proposition' is a necessary condition on being a main clause, an assumption common in the linguistic literature. If that condition is re laxed, it raises the question of how otherwise to distinguish MCs from CCs or DMs on semantic and syntactic grounds an issue that goes beyond the scope of this paper.

8. The ICE-GB corpus and accompanying material (Nelson, Wallis \& Aarts 2002) provides detailed information on the source of the corpus data. In the spoken part of the corpus, files with names beginning with $s 1 a$ are from the private domain, comprising speech material from di rect conversations (s1a-001 - s1a-090) and telephone conversations (s1a-091 - s1a-100). They thus represent casual, informal speech. Files with names beginning with $s 1 b, s 2 a$ or $s 2 b$ are from the public domain, representing more formal speech. They consist of dialogues (slb: classroom lessons, broadcast discussions and interviews, parliamentary debates, legal cross examinations, and business transactions), unscripted monologues (s2a: spontaneous commentaries, unscript ed speeches, demonstrations, and legal presentations), scripted monologues ( $\mathrm{s} 2 \mathrm{~b} 02 \mathrm{l} \quad \mathrm{s} 2 \mathrm{~b}$ 050: broadcast talks and non broadcast speeches), and a "mixed" category from broadcast news (s2b 001 s2b 020). See Appendix 2 to Nelson, Wallis \& Aarts (2002) for more information on the sources of the ICE GB texts.

9. The target sequences were often first within their utterances and thus within their sound files and a left edge did not therefore have to be identified. However, some target sequences were at the beginning of a coordinated clause or within an ongoing utterance, often preceded by a 
conjunction such as and, but or because, and left cdges were identified for those cases. Right boundaries were identified for all cases.

10. Note that due to the phonetic properties of the voiceless fricative as the onset of think it seems as if the main prominence might fall on think rather than $I$. However, this is not the case. The F0 disturbances between think and that and between Lord and Scarman are, moreover, due to the phonetic properties of the sounds involved: the plosive coda of think followed by a frica tive onset, and the voiceless fricative and plosive onset cluster of the first syllable of Scarman.

11. In our data set, no examples were found with prominence on both the pronoun and the verb at the same time. Based on the results reported here, we would predict that if two accents oc curred, the target sequence would function as a main clause.

12. Note that the reverse, i.e. that any propositional MC with a lst person subject pronoun has a main accent on this pronoun, is not true. In the present context, prosody is used to disambigu ate between syntactically ambiguous forms. If there is no such ambiguity, there is no need for prosodic disambiguation.

13. Found in The Guardian, Sat. 28 June 2008, Review section, p. 16.

14. Here again, our argument assumes that 'conveying the main proposition' is a necessary con dition for being a main clause (see also fn (8) above). This assumption also underlies much previous work, including the work referred to here.

\section{References}

Aijmer, Karin. 1997. I think an English modal particle. Modality in Germanic languages Historical and comparative perspectives, Toril Swan \& Olaf Jansen Westvik (eds.), 1 47. Ber lin/New York: Mouton de Gruyter.

Allerton, D.J. \& Alan Cruttenden. 1974. English sentence adverbials: Their syntax and their intonation in British English. Lingua 34: 130.

Austin, John L. 1962. How to do things with words (2nd edn). Cambridge, MA: Harvard Uni versity Press.

Beckman, Mary E. \& Janet B. Pierrehumbert. 1986. Intonational structure in Japanese and Eng lish. Phonology Yearbook 3: 255309.

Biber, D., S. Johansson, G. Leech, S. Conrad, \& Edward Finegan. 1999. Longman grammar of spoken and written English. London: Longman.

Blakemore, Diane. 1987. Semantic Constraints on Relevance. Oxford: Blackwell.

Blakemore, Diane. 2002. Relevance and Linguistic Meaning: The Semantics and Pragmatics of Discourse Markers. Cambridge: Cambridge University Press.

Blakemore, Diane. 2005. Discourse markers. The Handbook of Pragmatics, Laurence Horn \& Gregory Ward (eds.), 221240 . Oxford: Blackwell.

Boersma, Paul. 2001. Praat, a system for doing phonetics by computer. Glot International 5(9/10): 341347

Boersma, Paul \& David Weenink. 2008. Praat: doing phonetics by computer (Version 5.0.04) [Computer program]. http://www.praat.org/. Accessed 30 January 2008.

Bolinger, Dwight. 1972. That's that. The Hague, Paris: Mouton. 
Boye, Kasper \& Peter Harder. 2007. Complement taking predicates. Studies in Language 31(3): 569606.

Brinton, Laurel J. 1996. Prigmatic markers in English: Grammaticalization and discourse func tions (Topics in English Linguistics 19). Berlin/ New York: Mouton de Gruyter.

Brinton, Laurel J. 2008. The comment clause in English. Syntactic origins and pragmatic development. Cambridge: Cambridge University Press.

Bybee, Joan \& Joanne Scheibman. 1999. The effect of usage on degrees of constituency: The reduction of don't in English. Linguistics 37(4): 575596.

Croft, William. 2000. Exploring language change: an evolutionary approach. London: Longman.

Cruttenden, Alan. 1997. Intonation (2nd edn). Cambridge: Cambridge University Press.

Crystal, David. 1969. Prosodic systems and intonation in English. Cambridge: Cambridge Uni versity Press.

Crystal, David. 1972. The intonation system of English. Intonation: Selected readings, Dwight Bolinger (ed.), 110 136. Harmondsworth: Penguin.

Dehé, Nicole. 2009. Clausal parentheticals, intonational phrasing, and prosodic theory. Journal of Linguistics 45(3): 569615.

Dehé, Nicole \& Anne Wichmann. To appear. The multifunctionality of epistemic parentheticals in discourse: Prosodic cues to the semantic pragmatic boundary. Functions of Language.

Diessel, Holger \& Michael Tomasello. 2001. The acquisition of finite complement clauses in English: A corpus based analysis. Cognitive Linguistics 12(2): 97141.

Dor, Daniel. 2005. Toward a semantic account of that deletion in English. Linguistics 43(2): 345382.

Emonds, Joseph E. 1973. Parenthetical clauses. You take the high node and I'll take the low node, Claudia Corum, Cedrik Smith Stark \& Ann Weiser (eds.), 333 347. Chicago: Chicago Lin guistic Society.

Emonds, Joseph E. 1976. A transformational approach to English syntax. Root, structure preserv ing, and local transformations. New York, San Francisco \& London: Academic Press.

Ferreira, Fernanda. 1993. Creation of prosody during sentence production. Psychological Review 100(2): 233253.

Fischer, Olga. 2007. Morphosyntactic change: Functional and formal perspectives. Oxford: Oxford University Press.

Gee, James P. \& Francois Grosjean. 1983. Performance structures: A psycholinguistic and lin guistic appraisal. Cognitive Psychology 15: 411458.

Ghini, Mirco. 1993. Phi formation in Italian: A new proposal. Toronto Working Papers in Lin guistics 12: 4178 .

Grewendorf, Günther. 1988. Aspekte der deutschen Syntax: Eine Rektions Bindungs Analyse. Tübingen: Gunter Narr.

Grimshaw, Jane. 1991. Extended projections. Ms., Brandeis University

Grimshaw, Jane. 1997. Projection, heads and optimality. Linguistic Inquiry 28(3): 373422.

Gussenhoven, Carlos \& Rietveld, A.C.M. 1992. Intonation contours, prosodic structure and pre boundary lengthening. Journal of Phonetics 20: 283303.

Gussenhoven, Carlos. 2004. The phonology of tone and intonation. Cambridge: Cambridge Uni versity Press.

Haider, Hubert. 1993. ECP Etüden: Anmerkungen zur Extraktion aus eingebetteten Verb Zweit Sätzen. Linguistische Berichte 145: 185203.

Haiman, John. 1994. Ritualization and the development of language. Perspectives on Grammati calization. William Pagliuca (ed.), 3 28. Amsterdam: John Benjamins. 
Hawkins, John A. 2001. Why are categories adjacent? Journal of Linguistics 37: 134 .

Hirschberg, J., and D. Litman (1993) Empirical studies on the disambiguation of cue phrases. Computational Linguistics 19(3): 501530.

Hopper, Paul J. \& Elizabeth C. Traugott. 2003. Grammaticalization (2nd edn). Cambridge: Cam bridge University Press.

Jackendoff, Ray. 1972. Semantic interpretation in generative grammar. Cambridge, MA: MIT Press.

Jespersen, Otto. 1937. Analytic syntax. London: Allen and Unwin.

Kaltenböck, Gunther. 2006. '...That is the question': Complementizer omission in extraposed that clauses. English Language and Linguistics 10(2): 371396.

Kaltenböck, Gunther. 2007. Position, prosody, and scope: The case of English comment clauses. Vienna English Working Papers 16(1): 338.

Kärkkäinen, Elise. 2003. Epistemic stance in English conversation: A description of its interac tional functions, with a focus on I think. Amsterdam: Benjamins.

Kayne, Richard S. 1981. ECP Extensions. Linguistic Inquiry 12: 93133.

Kearns, Kate. 2007. Epistemic verbs and zero complementizer. English Language and Linguistics 11(3): 475505.

Kiziak, Tanja. 2007. Long extraction or parenthetical insertion? Evidence from judgement stud ies. Parentheticals, Nicole Dehé \& Yordanka Kavalova (eds.), 122 144. Amsterdam/Phila delphia: John Benjamins [Linguistik Aktuell/Linguistics Today 106].

Knowles, Gerry. 1991. Prosodic labelling: The problem of tone group boundaries. English Com puter Corpora. Selected Papers and Research Guide (Topics in English Linguistics 3), Stig Jo hansson \& Anna Brita Stenström (eds.), 149 161. Berlin/ New York: Mouton de Gruyter.

Krivokapić, Jelena. 2007. Prosodic planning: Effects of phrasal length and complexity on pause duration. Journal of Phonetics 35: 162179.

Ladd, D. Robert. 1986. Intonational phrasing: The case for recursive prosodic structure. Phonol ogy Yearbook 3: 311340 .

Ladd, D. Robert. 1996. Intonational phonology. Cambridge: Cambridge University Press.

Nelson, Gerald, Sean Wallis \& Bas Aarts. 2002. Exploring natural language: Working with the British component of the International Corpus of English. Amsterdam \& Philadelphia: John Benjamins.

Nespor, Marina \& Irene Vogel. 1986. Prosodic phonology Dordrecht: Foris [Studies in Generative Grammar 28]

Pesetsky, David. 1998. Some optimality principles of sentence pronunciation. Is the best good enough? Optimality and competition in syntax, Pilar Barbosa et al. (eds.), 337 383. Cam bridge, MA: MIT Press.

Peterson, Peter. 1999. On the boundaries of syntax. The clause in English, Peter Collins \& David Lee (eds.), 229 250. Amsterdam \& Philadelphia: John Benjamins.

Pierrehumbert, Janet. 1980. The phonology and phonetics of English intonation. Ph.D. diss, MIT.

Pierrehumbert, Janet \& Julia Hirschberg. 1990. The meaning of intonational contours in the interpretation of discourse. Intentions in communication, Philip R. Cohen, Jerry Morgan \& Martha E. Pollack (eds.), 271 311. Cambridge, MA: MIT Press.

Quirk, R., S. Greenbaum, G. Leech \& J. Svartvik (1985). A comprehensive grammar of the English language. Harlow: Longman.

Reis, Marga. 1995. Wer glaubst du hat recht? On so called extractions from verb second clauses and verb-first parenthetical constructions in German. Sprache und Pragmatik 36: 2783. 
Reis, Marga. 2002. Wh movement and integrated parenthetical constructions. Studies in Com parative Germanic Syntax, Proceedings from the 15th Workshop on Comparative Germanic Syntax, C. J. W. Zwart \& W. Abraham. (eds.), 3 40. Amsterdam: John Benjamins [Linguis tik Aktuell/Linguistics Today 53].

Ross, John R. 1973. Slifting. The formal analysis of natural languages. Proceedings of the first international conference, Maurice Gross, Morris Halle \& Marcel Paul Schützenberger (eds.), 133-169. The Hague/Paris: Mouton.

Schelfhout, Carla, Peter Arno Coppen \& Nelleke Oostdijk. 2004. Finite comment clauses in Dutch: A corpus based approach. Journal of Germanic Linguistics 16(4): 331350.

Schneider, Stefan. 2007a. Reduced parenthetical clauses in Romance languages A pragmatic typology. Parentheticals, Nicole Dehé \& Yordanka Kavalova (eds.), 237 255. Amsterdam/ Philadelphia: John Benjamins [Linguistik Aktuell/Linguistics Today 106].

Schneider, Stefan. 2007b. Reduced parenthetical clauses as initigators: A corpus study of spoken French, Italian and Spanish. Amsterdam/Philadelphia: John Benjamins.

Selkirk, Elisabeth. 1986. On derived domains in sentence phonology. Phonology Yearbook 3: 371405.

Selkirk, Elisabeth. 1995. Sentence prosody: Intonation, stress, and phrasing. The handbook of phonological theory, J.A. Goldsmith (ed.), 550 569. Oxford: Blackwell.

Selkirk, Elisabeth. 1996. The prosodic structure of function words. Signal to syntax: Bootstrap ping from speech to grammar in early acquisition, James L. Morgan \& Katherine Demuth (eds.), 187 213. Mahwak, NJ: Lawrence Erlbaum.

Selkirk, Elisabeth. 2000. The interaction of constraints on prosodic phrasing. Prosody: Theory and experiment, Merle Horne (ed.), 231261 . Dordrecht: Kluwer.

Shattuck Hufnagel, Stefanie \& Alice E. Turk. 1996. A prosody tutorial for investigators of audi tory sentence processing. Journal of Psycholinguistic Research 25(2): 193247.

Snyder, William \& Susan Rothstein. 1992. A note on contradiction, case and complementizers. The Linguistic Review 9(3): 251266.

Sperber, Dan \& Deirdre Wilson. 1986/1995. Relevance: Communication \& Cognition. Oxford: Blackwell.

Stowell, Timothy A. 1981. Origins of Phrase Structure. Ph.D. diss, Cambridge, MA: MIT.

Tappe, Hans Thilo. 1981. Wer glaubst du hat recht? Einige Bemerkungen zur COMP-COMPBewegung im Deutschen. Sprache: Formen und Strukturen. Akten des 15. Linguistischen Kolloquiums, Münster 1980, Vol. 1, Manfred Kohrt \& Jürgen Lenerz (eds.), 203 212. Tübin gen: Niemeyer [Linguistische Arbeiten 98].

Thompson, Sandra A. \& Anthony Mulac. 1991a. A quantitative perspective on the grammaticization of epistemic parentheticals in English. Approaches to grammaticalization: Vol. 2: Types of grammatical markers, E. Traugott, and B. Heine (eds.), 313 327. Amsterdam: Ben jamins [Typological Studies in Language, 19:2.].

Thompson, Sandra A. \& Anthony Mulac. 1991b. The discourse conditions for the use of the complementizer that in conversational English. Journal of Pragmatics 15: 237251.

Traugott, Elizabeth C. 1992. Syntax. The Cambridge History of the English Language, Vol. I: The Beginnings to 1066, Richard M. Hogg (ed.), 168 289. Cambridge: Cambridge University Press.

Truckenbrodt, Hubert. 1995. Phonological phrases: Their relation to syntax, focus, and prominence. Ph.D. diss, Cambridge, MA: MIT.

Truckenbrodt, Hubert. 1999. On the relation between syntactic phrases and phonological phrases. Linguistic Inquiry 30: 219255. 
Urmson, J.O. 1952. Parenthetical verbs. Mind 61: 480496

Urmson, J.O. 1963. Parenthetical verbs. Philosophy and Ordinary Language, C. E. Caton (ed.), 220 240. Urbana: University of Illinois Press.

Vaissière, Jacqueline. 1983. Language independent prosodic features. Prosody: Models and Mea surements. Anne Cutler \& D. Robert Ladd (eds.), 53 66. Berlin: Springer.

Wagner, Michael. 2004. Asymmetries in the syntax and prosody of verb initial interpolated clauses. Proceedings of Console XII. Sylvia Blaho; Luis Vicente \& Mark de Vos (eds.), 201 215. University of Leiden.

Wichmann, Anne, A. M. Simon Vandenbergen \& Karin Aijmer. To appear. How prosody re flects semantic change: A synchronic case study of of course. Subjectification, intersubjectification and grammaticalization, H. Cuyckens; K. Davidse \& L. Vandelanotte (eds.), Berlin/ New York: Mouton de Gruyter.

\section{Authors' addresses}

Nicole Déhé

Freie Universität Berlin Institut für Englische Philologie

Habelschwerdter Allee 45

14195 Berlin

Germany

ndehe@zedat.fu berlin.de

\author{
Anne Wichmann \\ School of Journalism, Media and \\ Communication \\ University of Central Lancashire \\ Preston PR 12HE \\ UK \\ awichmann@uclan.ac.uk
}

